\title{
Evidence-based clinical practice guidelines for peptic ulcer disease 2020
}

\author{
Tomoari Kamada ${ }^{1,2} \cdot$ Kiichi Satoh $^{2} \cdot$ Toshiyuki Itoh $^{2} \cdot$ Masanori Ito $^{2} \cdot$ \\ Junichi Iwamoto $^{2}$ - Tadayoshi Okimoto ${ }^{2}$ Takeshi Kanno ${ }^{2} \cdot$ Mitsushige Sugimoto $^{2}$ • \\ Toshimi Chiba $^{2} \cdot$ Sachiyo Nomura $^{2} \cdot$ Mitsuyo Mieda $^{2} \cdot$ Hideyuki Hiraishi $^{2} \cdot$ \\ Junji Yoshino $^{2} \cdot$ Atsushi Takagi $^{2} \cdot$ Sumio Watanabe $^{2} \cdot$ Kazuhiko Koike $^{2}$
}

Received: 7 October 2020/ Accepted: 3 February 2021/Published online: 23 February 2021

(C) The Author(s) 2021

\begin{abstract}
The Japanese Society of Gastroenterology (JSGE) revised the third edition of evidence-based clinical practice guidelines for peptic ulcer disease in 2020 and created an English version. The revised guidelines consist of nine items: epidemiology, hemorrhagic gastric and duodenal ulcers, Helicobacter pylori (H. pylori) eradication therapy, non-eradication therapy, drug-induced ulcers, non- $H$. pylori, and nonsteroidal anti-inflammatory drug (NSAID) ulcers, remnant gastric ulcers, surgical treatment, and conservative therapy for perforation and stenosis. Therapeutic algorithms for the treatment of peptic ulcers differ based on ulcer complications. In patients with NSAID-induced ulcers, NSAIDs are discontinued and antiulcer therapy is administered. If NSAIDs cannot be discontinued, the ulcer is treated with proton pump inhibitors (PPIs). Vonoprazan (VPZ) with antibiotics is recommended as the first-line treatment for $H$. pylori eradication, and PPIs or VPZ with antibiotics is recommended as a
\end{abstract}

The members of the Guidelines Committee are listed in the Appendix. The original version of this article appeared in Japanese as "Shokasei Kaiyo Sinryo Guideline 2020" from the Japanese Society of Gastroenterology (JSGE), published by Nankodo, Tokyo, in 2020. Please see the article on the standards, methods, and process of developing the guidelines.

Tomoari Kamada

tkamada@med.kawasaki-m.ac.jp

1 Department of Health Care Medicine, Kawasaki Medical School General Medical Center, 2-6-1, Nakasange, Kita-ku, Okayama 700-8505, Japan

2 Guidelines Committee for Creating and Evaluating the "Evidence-Based Clinical Practice Guidelines for Peptic Ulcer," the Japanese Society of Gastroenterology (JSGE), 6F Shimbashi i-MARK Bldg., 2-6-2 Shimbashi, Minato-ku, Tokyo 105-0004, Japan second-line therapy. Patients who do not use NSAIDs and are $H$. pylori negative are considered to have idiopathic peptic ulcers. Algorithms for the prevention of NSAIDand low-dose aspirin (LDA)-related ulcers are presented in this guideline. These algorithms differ based on the concomitant use of LDA or NSAIDs and ulcer history or hemorrhagic ulcer history. In patients with a history of ulcers receiving NSAID therapy, PPIs with or without celecoxib are recommended and the administration of VPZ is suggested for the prevention of ulcer recurrence. In patients with a history of ulcers receiving LDA therapy, PPIs or VPZ are recommended and the administration of a histamine 2-receptor antagonist is suggested for the prevention of ulcer recurrence.

Keywords Peptic ulcer - Helicobacter pylori eradication Nonsteroidal anti-inflammatory drug · Low-dose aspirin . Idiopathic ulcer

\section{Introduction}

In 2009, the Japanese Society of Gastroenterology (JSGE) developed evidence-based clinical practice guidelines for peptic ulcer disease. The guidelines were revised in 2015 and again in 2020. Of the 90 clinical questions (CQs) included in the previous guidelines, those with a clear conclusion were considered background questions (BQs) and those requiring future research were considered future research questions (FRQs) in this revised guideline. Thus, the revised guidelines consist of nine items (28 CQs and one FRQ), including, for the first time, epidemiology and remnant gastric ulcer. Both epidemiology and conservative therapy for perforation and stenosis included only BQ. The prevention of hemorrhagic peptic ulcers in patients taking 
antithrombotic drugs and the treatment of ischemic duodenal ulcers have been added as a CQ and FRQ, respectively.

A literature search of Medline and the Cochrane Library was performed for data regarding the CQs published between 1983 and October 2018, and the Igaku Chuo Zasshi databases were searched for data published between 1983 and December 2018. The guidelines were developed using the Grading of Recommendations Assessment, Development and Evaluation (GRADE) system [1]. The quality of evidence was graded as A (high), B (moderate), C (low), and D (very low). Recommendation strength was indicated as either a "strong recommendation", or a "weak recommendation', The systematic review (SR) team conducted meta-analysis (MA) and decided the total strength of the evidence from A to D. The consensus was previously defined as $70 \%$ or more votes in agreement.

In Japan, incidence of cerebral infarction and myocardial infarction are increasing, and many patients undergo antithrombotic therapy including dual antiplatelet therapy (DAPT). In endoscopic clinical practice, focus has shifted from the risk of gastrointestinal (GI) bleeding to thromboembolism associated with the withdrawal of antithrombotic therapy [2, 3]. In addition, for nearly 50 years, the only oral anticoagulants were vitamin $\mathrm{K}$ antagonists (warfarin); however, four non-vitamin $\mathrm{K}$ antagonist direct oral anticoagulants (DOACs) are currently available. The hemorrhagic gastric and duodenal ulcer section of the revised guidelines emphasizes methods for the discontinuation of antithrombotic therapy including DOACs and for the prevention of hemorrhagic ulcers in patients taking anticoagulant and antiplatelet drugs, such as DAPT.

Vonoprazan (VPZ) provides potent and long-lasting inhibition of gastric acid secretion, and its efficacy is, therefore, expected to be superior to that of proton pump inhibitors (PPIs). Recent reports have shown that triple therapy including VPZ is as effective as first-line and second-line therapies for the eradication of Helicobacter pylori [4]. Several reports have indicated that VPZ effectively heals peptic ulcers [5] and prevents the recurrence of nonsteroidal anti-inflammatory drugs (NSAIDs) [6] and low-dose aspirin (LDA)-related ulcers [7]. This revised version also emphasizes the clinical results of VPZ.

\section{Hemorrhagic gastric and duodenal ulcers}

\section{Non-endoscopic hemostatic therapy}

\section{$C Q-1$}

Treatment of with patients with hemorrhagic peptic ulcers if they prescribed anticoagulants and/or antiplatelet agents?
- Recommended that aspirin be continued for conditions at high risk for thromboembolic events.

Recommendation: strong, $100 \%$ agreed, evidence level B.

- Suggested to change antiplatelet agents to aspirin in patients with conditions with a high risk of thromboembolic events.

Recommendation: weak, $100 \%$ agreed, evidence level D.

- Suggested to suspend antiplatelet agents, except for in patients at high risk for thromboembolic events.

Recommendation: weak, $100 \%$ agreed, evidence level D.

- Recommended to suspend warfarin, if necessary, in endoscopic hemostasis patients. If warfarin is discontinued, we suggest heparin or resuming warfarin as soon as hemostasis is established.

Recommendation: strong, $100 \%$ agreed, evidence level C.

- Suggested to resume DOACs early (within 1-2 days) after confirming endoscopic hemostasis.

Recommendation: weak, $100 \%$ agreed, evidence level D.

- In patients receiving both antiplatelet agents and warfarin, suggested to change antiplatelet agents to aspirin or cilostazol. Continue warfarin under a suitable prothrombin time-international normalized ratio (PT-INR) or to change warfarin to heparin.

Recommendation: weak, $100 \%$ agreed, evidence level D.

- In patients receiving dual antiplatelet agents, recommended that aspirin alone should be continued.

Recommendation: strong, $100 \%$ agreed, evidence level D.

Comment: The risk of re-bleeding due to continuing anticoagulant and/or antiplatelet agents and the risk of thromboembolism associated with their withdrawal should be considered. One randomized controlled trial (RCT) [8] reported significantly lower mortality in the continuing LDA group compared with the group that did not. However, clinical evidence is currently lacking to support the management of patients who receive antiplatelet agents excluding aspirin, warfarin, and DOACs with peptic ulcer bleeding (PUB). We considered that these recommendations are based on expert opinions of the guidelines of Japan Gastroenterological Endoscopy, Asia-Pacific working group and European Society of Gastroenterological Endoscopy. It is necessary to collaborate closely with gastroenterologists and cardiologists as patients at high risk of thromboembolism with PUB could be unstable. 
$C Q-2$

Is interventional radiology (IVR) effective in patients undergoing refractory endoscopic treatment for hemorrhagic peptic ulcers?

- In patients undergoing refractory endoscopic treatment for hemorrhagic peptic ulcers, interventional radiology (IVR) is suggested due to its safety and effectiveness. Recommendation: weak, $100 \%$ agreed, evidence level C.

Comment: The effectiveness of IVR with transcatheter arterial embolization was proven by two MAs $[9,10]$. They reported that compared to surgery, IVR exhibits a higher re-bleeding rate, but no significant difference in mortality, need for additional interventions, or complication rates between treatments. IVR could be a viable option for the treatment of refractory PUB; however, a limited number of institutions can perform IVR.

\section{$C Q-3$}

Is medication with antacid agents required after endoscopic treatment for hemorrhagic peptic ulcers?

- PPI administration after endoscopic treatment for hemorrhagic peptic ulcers is recommended to improve treatment outcomes.

Recommendation: strong, $100 \%$ agreed, evidence level A.

Comment: Compared with placebo, intravenous PPI therapy after endoscopic treatment for hemorrhagic peptic ulcers has been proven to reduce the rate of rebleeding, volume of blood transfusion, period of admission, and rate of conversion to surgery in two MAs [11, 12] and some randomized controlled trials. The efficacy of high-dose PPI therapy is not higher than non-high-dose PPI regarding decreasing re-bleeding, surgical intervention, or mortality after post-endoscopic hemostasis [13].

There was no significant difference effect between oral and intravenous PPI therapy on mortality, re-bleeding, need for blood transfusion, length of hospital stays, or surgery [14].

Compared to intravenous histamine 2-receptor antagonist $\left(\mathrm{H}_{2} \mathrm{RA}\right)$ therapy, PPI therapy reduces rates of ulcer re-bleeding, surgical intervention, and overall duration of hospital stay with no significant difference in mortality [15]. Considering patient benefits, we recommended PPI therapy after endoscopic treatment for hemorrhagic peptic ulcers.

\section{Prevention of hemorrhagic peptic ulcer}

$C Q-4$

What drugs are recommended for the prevention of hemorrhagic ulcers in antithrombotic users?

- In DAPT, we recommend the combined use of PPIs to prevent upper gastrointestinal bleeding (UGIB).

Recommendation: strong, $100 \%$ agreed, evidence level A.

- If taking warfarin, we suggest using PPIs to prevent UGIB in patients taking antiplatelet drugs or NSAIDs in combination.

Recommendation: weak, $100 \%$ agreed, evidence level C.

(PPI is not covered by Japanese insurance for primary prevention of PUB in patients taking LDA or NSAIDs). Comment: MAs of RCTs aimed to determine whether the combination of PPIs is useful for the prevention of UGIB in DAPT with clopidogrel and aspirin. In addition to the large randomized COGENT trial [16], an MA was conducted involving three studies (two RCTs) $[17,18]$ comparing PPI usage. PPIs significantly prevented UGIB (risk ratio [RR] 0.26; 95\% confidence interval $[\mathrm{CI}]$ 0.13-0.53, $P=0.0002$ ) (Fig. 1). There was no significant difference in major adverse cardiovascular events, with or without PPI (RR 1.01; 95\% CI $0.80-1.26, P=0.96$ ). In the 2017 focused update on DAPT in coronary artery disease of the European Society of Cardiology, PPIs in combination with DAPT were recommended (recommendation class I) [19].

Only observational studies were available regarding the UGIB preventive effect of PPI in patients taking warfarin. Ray et al. [20], in large retrospective cohort study, found that PPI administration significantly reduced the risk of hospitalization for UGIB in patients receiving warfarin with concomitant antiplatelet drugs or NSAIDs (45\% reduction (hazard ratio $0.55 ; 95 \%$ CI 0.39-0.77), $P=0.0004)$.

\section{H. pylori eradication therapy}

\section{First-line eradication therapy}

$C Q-5$

What kind of regimen should we select for first-line $H$. pylori eradication therapy?

- As triple eradication therapy using VPZ with amoxicillin and clarithromycin has a high eradication rate 


\begin{tabular}{|c|c|c|c|c|c|c|c|c|c|c|c|}
\hline Study or Subgroup & \multicolumn{2}{|l|}{ PPI } & \multicolumn{2}{|c|}{ Control } & \multicolumn{3}{|c|}{ Risk Ratio } & \multicolumn{4}{|c|}{$\begin{array}{c}\text { Risk Ratio } \\
\text { M-H, Random, } 95 \% \mathrm{Cl}\end{array}$} \\
\hline Bhatt & 8 & 1876 & 26 & 1885 & $82.3 \%$ & $0.31[0.14,0.68]$ & 2010 & & $7-$ & & \\
\hline Ren & 0 & 86 & 2 & 86 & $5.6 \%$ & $0.20[0.01,4.11]$ & 2011 & & & & \\
\hline Wei & 1 & 123 & 8 & 84 & $12.1 \%$ & $0.09[0.01,0.67]$ & 2016 & & & & \\
\hline Total $(95 \% \mathrm{Cl})$ & & 2085 & & 2055 & $100.0 \%$ & $0.26[0.13,0.53]$ & & & & & \\
\hline Total events & 9 & & 36 & & & & & & & & \\
\hline $\begin{array}{l}\text { Heterogeneity: Tau } \\
\text { Test for overall effeo }\end{array}$ & $\begin{array}{l}0.00 ; \mathrm{Ch} \\
\mathrm{Z}=3.70\end{array}$ & $\begin{array}{l}P^{2}=1.3 \\
P=0.0\end{array}$ & $\begin{array}{l}5, \mathrm{df}=2( \\
1002)\end{array}$ & $P=0.5$ & 1); $\left.\right|^{2}=0 x$ & & & 0.01 & $\begin{array}{l}0.1 \\
\text { Favours PPI }\end{array}$ & $\begin{array}{cc}10 \\
\text { Favours Control }\end{array}$ & $\overrightarrow{100}$ \\
\hline
\end{tabular}

Fig. 1 Forest plots of proton pump inhibitors (PPIs) against control for upper gastrointestinal bleeding preventive effect in dual antiplatelet therapy (DAPT). In meta-analysis, PPIs significantly have reduced bleeding risk compared to controls (RR $0.26 ; 95 \% \mathrm{CI} 0.13-0.53, P=0.0002)$

compared with that of PPIs, VPZ is recommended as a first-line therapy.

Recommendation: strong, $100 \%$ agreed, evidence level A.

- The recommended antibiotics for first-line therapy include amoxicillin, clarithromycin, or metronidazole. In Japan, the combination of amoxicillin and metronidazole is recommended due to the high incidence rate of clarithromycin-resistant strains (not covered by the Japanese insurance system).

Recommendation: strong, $100 \%$ agreed, evidence level A.

- When PPIs are used, sequential therapy and concomitant quadruple therapy are suggested due to the high eradication rate in the first-line therapy compared with triple therapy (not covered by the Japanese insurance system).

Recommendation: weak, $100 \%$ agreed, evidence level A.

Comment: In the Japanese insurance system, triple therapy with a PPI or VPZ, amoxicillin, and clarithromycin is used as first-line therapy [21]. As the degree and duration of acid inhibition are related to the cure rate of $H$. pylori [22], an MA compared the efficacy of VPZ-containing therapies to PPI-containing therapies (Fig. 2) [23]. In areas with high clarithromycin-resistance rates $(>15 \%)$, the Maastricht V/Florence Consensus Report suggested that when culture/sensitivity testing is not performed before eradication, first-line therapy using clarithromycin should not be used; bismuth quadruple (PPI/bismuth/ tetracycline/metronidazole) or concomitant quadruple therapy (PPI/amoxicillin/clarithromycin/nitroimidazole or metronidazole) is recommended [24]. In addition, in areas with low metronidazole- and high clarithromycinresistance rates, PPI/amoxicillin/metronidazole has a higher eradication rate than PPI/amoxicillin/clarithromycin (Fig. 3) [25].

\section{Second-line eradication therapy}

$C Q-6$

What regimen should we select for second-line $H$. pylori eradication therapy?

- Triple therapy with PPI/VPZ, amoxicillin, and metronidazole is recommended.

Recommendation: strong, $100 \%$ agreed, evidence level A.

Comment: Two MAs [26, 27] found that tetracycline/ quinolone-based quintuple or quadruple therapies were more effective than other therapies. One RCT revealed that levofloxacin sequential therapy was more effective than levofloxacin triple therapy [28]. These drugs have not been approved for $H$. pylori eradication therapy in

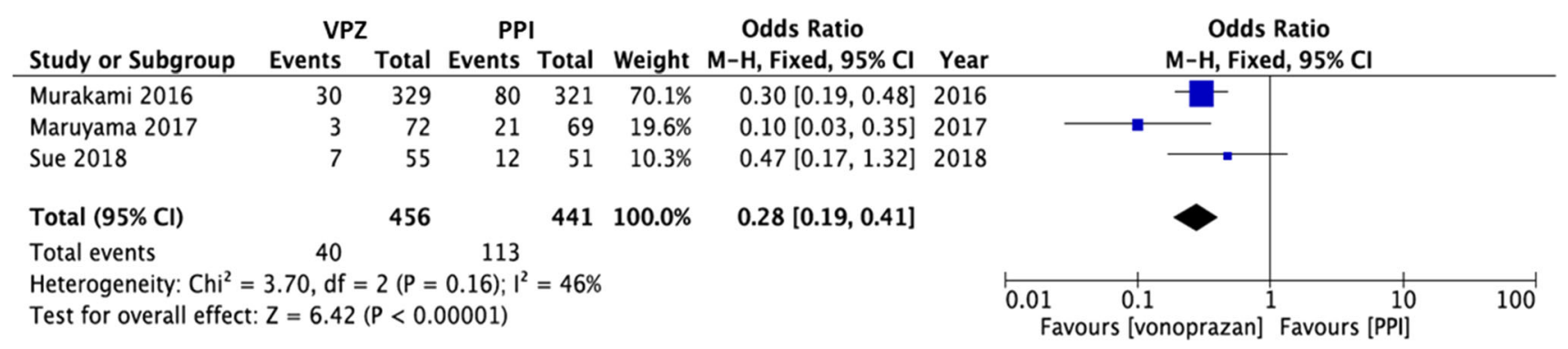

Fig. 2 Forest plots of eradication rates of first-line therapy between vonoprazan-containing triple therapy and proton pump inhibitor (PPI)-containing triple therapy in the randomized control trials. In meta-analysis, the eradication rates of vonoprazan-containing triple therapy are significantly higher than that of PPI-containing triple therapy (odds ratio 0.28 ; $95 \%$ CI $0.19-0.41, P<0.00001$ ) 


\begin{tabular}{|c|c|c|c|c|c|c|c|c|c|c|}
\hline \multirow[b]{2}{*}{ Study or Subgroup } & \multicolumn{2}{|c|}{ PAM } & \multicolumn{2}{|c|}{ PAC } & \multicolumn{3}{|c|}{ Odds Ratio } & \multirow{2}{*}{\multicolumn{3}{|c|}{$\begin{array}{c}\text { Odds Ratio } \\
\text { M-H, Fixed, 95\% Cl }\end{array}$}} \\
\hline & Events & Total & Events & Total & Weight & $\mathrm{M}-\mathrm{H}$, Fixed, $95 \% \mathrm{Cl}$ & Year & & & \\
\hline Nishizawa 2015 & 6 & 64 & 16 & 60 & $17.6 \%$ & $0.28[0.10,0.79]$ & 2015 & - & & \\
\hline Adachi 2017 & 6 & 72 & 20 & 68 & $22.2 \%$ & $0.22[0.08,0.58]$ & 2017 & & & \\
\hline Mabe 2018 & 6 & 169 & 48 & 137 & $60.2 \%$ & $0.07[0.03,0.17]$ & 2018 & & & \\
\hline Total $(95 \% \mathrm{Cl})$ & & 305 & & 265 & $100.0 \%$ & $0.14[0.08,0.24]$ & & & & \\
\hline Total events & 18 & & 84 & & & & & & & \\
\hline $\begin{array}{l}\text { Heterogeneity: } \mathrm{Chi}^{2}= \\
\text { Test for overall effec }\end{array}$ & $\begin{array}{l}5.17, \mathrm{df} \\
Z=7.18\end{array}$ & $\begin{array}{l}2(P= \\
<0 . C\end{array}$ & $\begin{array}{l}0.08) ; 1^{2} \\
0001)\end{array}$ & $=61 \%$ & & & & $\begin{array}{l}0.1 \\
\text { Favours [PAM] }\end{array}$ & Favours [PAC] & 100 \\
\hline
\end{tabular}

Fig. 3 Forest plots of eradication rates of second-line therapy between proton pump inhibitor/amoxicillin/metronidazole (PAM) therapy and proton pump inhibitor/amoxicillin/clarithromycin

Japan. In addition, the rate of $H$. pylori infection with primary resistance to levofloxacin is high in Japan. The eradication rate of triple therapy with PPI/VPZ, amoxicillin, and metronidazole is still high [4], and does not differ between the two regimens [29-31].

\section{Third-line eradication therapy}

$C Q-7$

What regimen should we select for third-line $H$. pylori eradication therapy?

- Triple therapy with PPI, sitafloxacin, and metronidazole or PPI, sitafloxacin, and amoxicillin is suggested (not covered by the Japanese insurance system).

Recommendation: weak, $100 \%$ agreed, evidence level B.

Comment: Three Japanese RCTs of third-line therapies showed that the eradication rates were 70.0-90.9\% [32-34]. The eradication rate of triple therapy with PPI, sitafloxacin, and metronidazole was 70.0-88.9\% [32-34], and that of PPI, sitafloxacin, and amoxicillin was 72.4-90.9\% [33, 34]. Because these eradication rates were not high enough, these regimens are not recommended, but suggested.

\section{Ulcer recurrence after $\boldsymbol{H}$. pylori eradication}

\section{$C Q-8$}

Is maintenance treatment necessary for the recurrence of peptic ulcer after successful $H$. pylori eradication?

- When the cause of peptic ulcer recurrence is unclear, long-term maintenance treatment with PPIs or $\mathrm{H}_{2}$ RAs is suggested.

Recommendation: weak, $100 \%$ agreed, evidence level D.

Comment: There are currently no published RCTs or MAs. Causes of the recurrence of peptic ulcers after
(PAC) therapy in the randomized control trials in Japan. In metaanalysis, the eradication rates of PAM therapy are significantly higher than that of PAC therapy (odds ratio 0.14 ; $95 \%$ CI $0.08-0.24$ )

successful $H$. pylori eradication include using LDA and NSAIDs, reinfection with $H$. pylori, and smoking habits. To prevent peptic ulcer recurrence, the exclusion of these factors is necessary. Idiopathic peptic ulcers are thought to be one of unknown causes of peptic ulcers after successful $H$. pylori eradication; therefore, long-term maintenance treatment with PPIs or $\mathrm{H}_{2} \mathrm{RAs}$ is suggested, when the cause of peptic ulcer recurrence is unclear.

\section{Non-eradication therapy}

Initial therapy.

\section{Gastric ulcer}

$C Q-9$

What is the first-line drug for the initial non-eradication treatment of gastric ulcers?

- Either PPIs or P-CAB is recommended.

Recommendation: strong, $100 \%$ agreed, evidence level A.

- If PPIs and P-CAB cannot be prescribed, $\mathrm{H}_{2} \mathrm{RAs}$ are recommended.

Recommendation: strong, $100 \%$ agreed, evidence level B.

- If PPIs and P-CAB cannot be prescribed, pirenzepine, sucralfate, and misoprostol are suggested.

Recommendation: weak, $100 \%$ agreed, evidence level B.

- If the above drugs cannot be prescribed, gastric mucosa-protecting agents (excluding sucralfate and misoprostol) are suggested.

Recommendation: weak, $100 \%$ agreed, evidence level B.

Comment: We recommend either PPIs or P-CAB due to their demonstrated ulcer healing rate of PPIs being significantly higher than that of $\mathrm{H}_{2}$ RAs [35-38]. 
P-CAB gained popularity in recent years due to their high ulcer healing rate for gastric ulcers compared with lansoprazole [39]. When PPIs and P-CAB cannot be prescribed, $\mathrm{H}_{2} \mathrm{RAs}$ are recommended. There were no reported significant differences in ulcer healing rates between $\mathrm{H}_{2}$ RAs. Moreover, pirenzepine, sucralfate, and misoprostol are suggested as their ulcer healing rates are equivalent to those of $\mathrm{H}_{2} \mathrm{RAs}$.

\section{Duodenal ulcer}

CQ-10

What is the first-line drug for the initial non-eradication treatment of duodenal ulcer?

- Either PPIs or P-CAB is recommended.

Recommendation: strong, $100 \%$ agreed, evidence level A.

- If PPIs and P-CAB cannot be prescribed, $\mathrm{H}_{2} \mathrm{RAs}$ are recommended.

Recommendation: strong, $100 \%$ agreed, evidence level B.

- If PPIs and P-CAB cannot be prescribed, pirenzepine, sucralfate, and misoprostol are suggested.

Recommendation: weak, $100 \%$ agreed, evidence level B.

Comment: We recommend either PPIs or P-CAB as the ulcer healing rate of PPIs is significantly higher than that of $\mathrm{H}_{2} \mathrm{RAs}$ [40]. P-CAB gained popularity in recent years due to their high ulcer healing rate for duodenal ulcers compared with lansoprazole [39]. When PPIs cannot be prescribed, $\mathrm{H}_{2} \mathrm{RAs}$ are recommended.

\section{Drug-induced ulcer}

Nonselective NSAID-induced ulcer.

\section{Treatment}

$C Q-11$

How should NSAID-induced ulcers be treated?

- NSAIDs should be discontinued, and administration of anti-ulcer drugs is recommended.

Recommendation: strong, $100 \%$ agreed, evidence level A.

- If NSAIDs cannot be discontinued, administration of PPIs is recommended as a first-line therapy.

Recommendation: strong, $100 \%$ agreed, evidence level A.
Comment: Gastric and duodenal ulcers in NSAID users heal to a high rate when NSAIDs are withdrawn [41]. In comparative studies of PPIs vs. $\mathrm{H}_{2} \mathrm{RA}$ [42] and PPIs vs. PG analogs [43], the healing rate of gastric and duodenal ulcers was highest in PPI groups. The original MA in this guideline indicated that the healing rate of peptic ulcers over 8 weeks was higher in PPI groups than in $\mathrm{H}_{2} \mathrm{RA}$ groups; thus PPIs are recommended as the first-line therapy (Fig. 4).

\section{Prevention}

\section{$C Q-12$}

If a patient receiving NSAIDs tests positive for $H$. pylori infection, should $H$. pylori eradication therapy be administered?

- Eradication of H. pylori is recommended for prevention of ulcers in NSAID-naïve patients.

Recommendation: strong, $100 \%$ agreed, evidence level A.

Comment: In comparative studies of PPIs and $\mathrm{H}$. pylori eradication, PPIs are superior to the eradication of $H$. pylori in preventing recurrent bleeding in patients taking NSAIDs [44].

Studies have $[45,46]$ indicated that $H$. pylori eradication therapy reduces the incidence of ulcers in patients receiving NSAIDs; however, an effect of $H$. pylori eradication therapy on preventing peptic ulcer cannot be expected during NSAID therapy. In an MA reported in 2012, the efficacy of $H$. pylori eradication therapy for preventing peptic ulcer was observed, especially in naïve users and in Asian populations [46].

$C Q-13$

Is preventive therapy for NSAID-induced ulcers necessary in patients with no history of ulcers?

- Prevention of NSAID-induced ulcers by administration of PPIs is necessary and suggested even in patients with no history of ulcers.

Recommendation: weak, $100 \%$ agreed, evidence level A.

(PPIs are not covered by Japanese insurance for primary prevention of ulcers in patients taking NSAIDs).

Comment: In patients receiving NSAID therapy for more than three months, the efficacy of PG analogs [47], PPIs [48], or high-dose $\mathrm{H}_{2} \mathrm{RAs}$ [49] given as primary preventions has been reported. Scally B et al. [50] showed that PPIs had larger protective effects than 


\begin{tabular}{|c|c|c|c|c|c|c|c|c|c|c|}
\hline \multirow[b]{2}{*}{ Study or Subgroup } & \multicolumn{2}{|c|}{ PPI } & \multicolumn{2}{|c|}{ H2RA } & \multicolumn{3}{|c|}{ Odds Ratio } & \multirow{2}{*}{\multicolumn{2}{|c|}{$\begin{array}{c}\text { Odds Ratio } \\
\text { M-H, Fixed, } 95 \% \mathrm{Cl}\end{array}$}} & \\
\hline & Events & Total & Events & Total & Weight & M-H, Fixed, 95\% Cl & & & & \\
\hline Agrawal 2000 & 37 & 118 & 54 & 115 & $23.1 \%$ & $0.52[0.30,0.88]$ & & $\rightarrow-$ & & \\
\hline Campbell 2002 & 75 & 226 & 113 & 225 & $46.6 \%$ & $0.49[0.34,0.72]$ & & -1 & & \\
\hline Goldstein 2007 & 21 & 138 & 33 & 139 & $17.2 \%$ & $0.58[0.31,1.06]$ & & 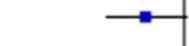 & & \\
\hline Yeomans 1998 & 9 & 67 & 25 & 70 & $13.0 \%$ & $0.28[0.12,0.66]$ & & & & \\
\hline Total $(95 \% \mathrm{Cl})$ & & 549 & & 549 & $100.0 \%$ & $0.48[0.37,0.63]$ & & & & \\
\hline Total events & 142 & & 225 & & & & & & & \\
\hline $\begin{array}{l}\text { Heterogeneity: } \mathrm{Chi}^{2}= \\
\text { Test for overall effect }\end{array}$ & $\begin{array}{l}1.97, \mathrm{df}= \\
Z=5.42\end{array}$ & $\begin{array}{l}3(P=0 \\
P<0.0\end{array}$ & $\begin{array}{l}0.58) ; 1^{2}= \\
10001)\end{array}$ & $=0 \%$ & & & 0.01 & $\mathrm{PPI}$ & 10 & 100 \\
\hline
\end{tabular}

Fig. 4 Meta-analysis of comparison of ulcer curative effect between PPI and $\mathrm{H}_{2} \mathrm{RA}$ under the NSAIDs continuation. In meta-analysis, the healing rate of peptic ulcers for 8 weeks is higher in the PPI groups than in the $\mathrm{H}_{2} \mathrm{RA}$ groups

$\mathrm{H}_{2} \mathrm{RAs}$ or PG analogs for peptic ulcers and further bleeding; therefore, PPIs are suggested as a first-line therapy.

\section{CQ-14}

How should recurrence be prevented in patients with a history of ulcers or bleeding ulcers who are starting NSAID therapy?

- PPIs are recommended, and VPZ is suggested to prevent NSAID-induced ulcers in patients with a history of ulcers.

Recommendation: weak, $100 \%$ agreed, evidence level B.

- Concomitant administration of the selective cyclooxygenase (COX)-2 inhibitor with a PPI is recommended for preventing recurrence of bleeding NSAID-induced ulcers in patients with a history of bleeding ulcers.

Recommendation: strong, $100 \%$ agreed, evidence level B.

Comment: Although the efficacy of PG analogs [51] for secondary prevention was observed in high-risk patients with a history of peptic ulcers, patient dropout due to diarrhea is common.

Studies found that PPIs were superior to placebos in reducing the risk of gastric or duodenal ulcer recurrence in patients with a history of ulcers requiring long-term NSAID therapy [52, 53]. The original MA in this guideline indicated that the recurrence rate of peptic ulcers in patients with a history of ulcers requiring long-term NSAID therapy was lower in PPI groups than in placebo groups. Therefore, PPIs are recommended as the first-line therapy (Fig. 5).

Chan et al. [54] suggested that combination treatment with a selective COX-2 inhibitor and a PPI was more effective than a selective COX-2 inhibitor alone for prevention of ulcer bleeding in patients at high risk.

Mizokami et al. [6] reported that VPZ was not inferior to PPIs, indicating that VPZ can be recommended for the second prevention of NSAID-induced peptic ulcer as well as PPIs.

\section{$C Q-15$}

How should NSAID-induced ulcers be prevented in patients receiving high-dose NSAIDs or a combination of NSAIDs and antithrombotic drugs or glucocorticoids or bisphosphonates, who are elderly, or have severe complications?

- In patients receiving combinations of NSAIDs and glucocorticoids or antithrombotic drugs, administration of a COX-2 inhibitor is recommended for ulcer prevention.

Recommendation: strong, $100 \%$ agreed, evidence level B.

- In elderly or patients with severe complications, administration of PPIs is recommended for the prevention of NSAID-induced ulcers.

Recommendation: strong, $100 \%$ agreed, evidence level A.

Comment: Concomitant use of nonselective NSAIDs or LDA, but not selective COX-2 inhibitors, with corticosteroids, or anticoagulants, increases the risk of UGIB, indicating that selective COX-2 inhibitors do not increase the risk of UGIB [55]. The efficacy of PPIs for prevention of complications has been demonstrated in a previous study [56].

Selective NSAID (COX-2 selective inhibitor)-induced ulcers.

$C Q-16$

Is a COX-2 selective inhibitor useful for the prevention of NSAID-induced ulcers?

- COX-2 selective inhibitors are recommended for the prevention of NSAID-induced ulcers.

Recommendation: strong, $100 \%$ agreed, evidence level 


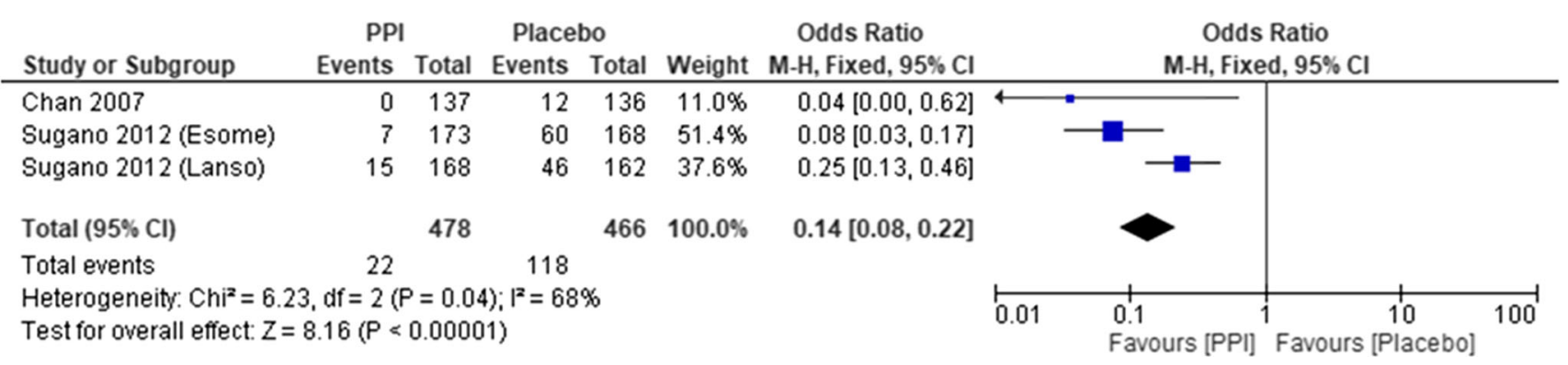

Fig. 5 Meta-analysis of preventive effect in the secondary prevention of NSAIDs ulcer. In meta-analysis, the recurrence rate of peptic ulcers in patients with a history of gastric or duodenal ulcers who required long-term NSAID therapy is lower in the PPI groups than in the placebo groups

A.

Comment: The incidence rate of peptic ulcers in Western countries is significantly lower in patients taking COX-2 selective inhibitors than in patients taking nonselective NSAIDs [57-59]. We conducted an
MA and found that the incidence of gastric ulcers (RR $0.21 ; 95 \%$ CI $0.18-0.25, P<0.00001$ ) (Fig. 6a) and duodenal ulcers (RR 0.38; 95\% CI 0.29-0.51, $P<0.00001$ ) (Fig. 6b) was lower in patients using COX-2 selective inhibitors than in patients using

(a)

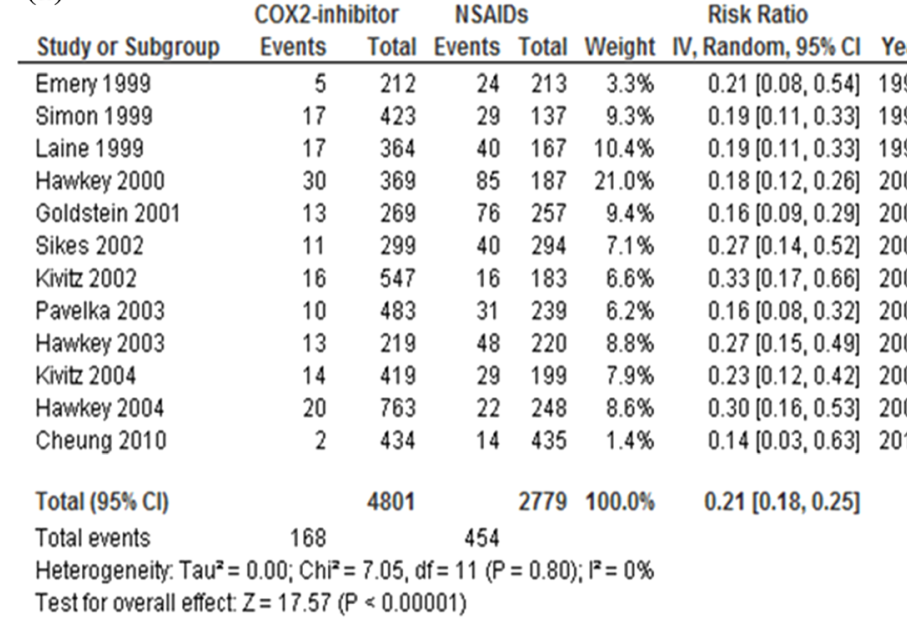

(b)

\begin{tabular}{|c|c|c|c|c|c|c|c|}
\hline \multirow{2}{*}{ Study or Subgroup } & \multicolumn{2}{|c|}{ COX-2 inhibitor } & \multicolumn{2}{|c|}{ NSAIDs } & \multicolumn{3}{|c|}{ Risk Ratio } \\
\hline & Events & Total & Events & Total & Weight & IV, Fixed, $95 \% \mathrm{Cl}$ & Year \\
\hline Laine 1999 & 5 & 364 & 10 & 167 & $7.3 \%$ & $0.23[0.08,0.66]$ & 199 \\
\hline Simon 1999 & 6 & 423 & 8 & 137 & $7.6 \%$ & $0.24[0.09,0.69]$ & 1999 \\
\hline Emery 1999 & 4 & 212 & 15 & 218 & $7.0 \%$ & $0.27[0.09,0.81]$ & 1999 \\
\hline Hawkey 2000 & 15 & 369 & 10 & 187 & $13.5 \%$ & $0.76[0.35,1.66]$ & 20 \\
\hline Goldstein 2001 & 9 & 269 & 19 & 267 & $13.7 \%$ & $0.47[0.22,1.02]$ & 20 \\
\hline Kivitz 2002 & 5 & 547 & 2 & 183 & $3.1 \%$ & $0.84[0.16,4.27]$ & 200 \\
\hline Sikes 2002 & 3 & 299 & 13 & 294 & $5.3 \%$ & $0.23[0.07,0.79]$ & 20 \\
\hline Hawkey 2003 & 2 & 219 & 11 & 220 & $3.7 \%$ & $0.18[0.04,0.81]$ & \\
\hline Pavelka 2003 & 12 & 483 & 14 & 239 & $14.4 \%$ & $0.42[0.20,0.90]$ & 20 \\
\hline Hawkey 2004 & 9 & 763 & 20 & 248 & $13.7 \%$ & $0.15[0.07,0.32]$ & 20 \\
\hline Kivitz 2004 & 4 & 632 & 2 & 199 & $2.9 \%$ & $0.63[0.12,3.41]$ & \\
\hline Cheung 2010 & 9 & 377 & 6 & 360 & $7.9 \%$ & $1.43[0.52,3.98]$ & \\
\hline Total $(95 \% \mathrm{Cl})$ & & 4957 & & 2719 & $100.0 \%$ & $0.38[0.29,0.51]$ & \\
\hline Total events & 83 & & 130 & & & & \\
\hline \multicolumn{8}{|c|}{ Heterogeneity. $\mathrm{Chi}^{2}=20.47, \mathrm{df}=11(P=0.04) ; \mathrm{I}^{2}=46 \%$} \\
\hline \multicolumn{7}{|c|}{ Test for overall effect: $Z=6.60(P<0.00001)$} & \\
\hline
\end{tabular}

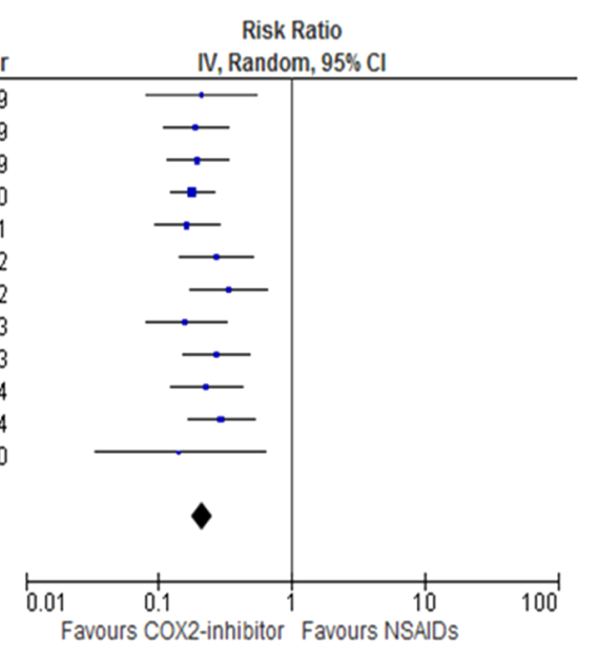

$\begin{array}{llc}01 & 0.1 & 10 \\ \text { Favours COX2-inhibitor } & \text { Favours NSAIDS }\end{array}$

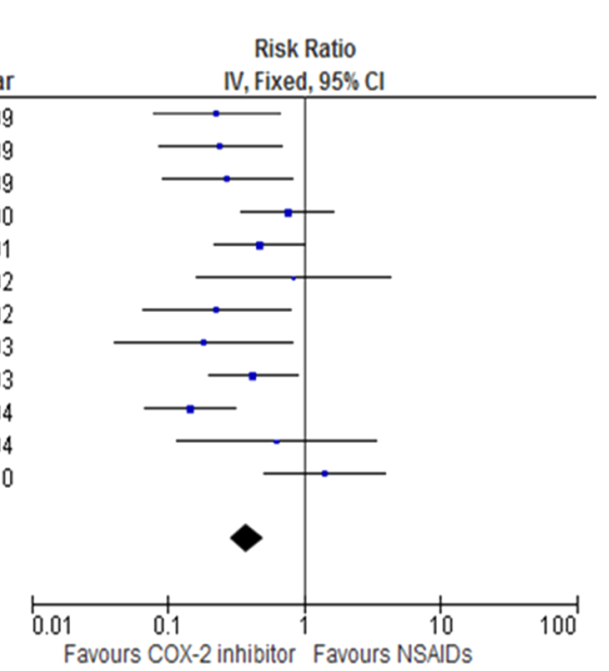

Fig. 6 Forest plots of peptic ulcer risk between COX-2 selective inhibitor and NSAID therapy in the randomized control trials (a gastric ulcer, b duodenal ulcer). In meta-analysis, the incidence

of gastric (risk ratio 0.21 ; 95\% CI 0.18-0.25) (a) and duodenal ulcers (risk ratio 0.38 ; 95\% CI 0.29-0.51) (b) are lower in patients using COX-2 selective inhibitors than in patients using NSAIDs 
NSAIDs. Using COX-2 selective inhibitors had a lower risk of developing serious ulcer complications.

A RCT including healthy Japanese volunteers showed that the incidence of gastroduodenal ulcers was $1.4 \%$, $27.6 \%$, and $2.7 \%$ in the celecoxib, loxoprofen, and placebo groups, respectively $(P<0.0001$ in favor of the celecoxib group) [60]. We conducted an MA and found that the incidence of peptic ulcers was lower in patients using COX-2 selective inhibitors than in patients using NSAIDs (RR 0.13 ; 95\% CI 0.04-0.44, $P=0.0010)$, similar to findings from patients in Western countries. These results indicate that COX-2 selective inhibitors are useful for the prevention of NSAID-induced ulcers and serious ulcer complications.

\section{$C Q-17$}

Is preventive medication with anti-ulcer agents required for patients taking a COX-2 selective inhibitor?

- Prevention with anti-ulcer agents is recommended for patients taking COX-2 selective inhibitors with a history of peptic ulcers or hemorrhage.

Recommendation: strong, $100 \%$ agreed, evidence level B.

- No prevention with anti-ulcer agents is recommended for patients taking COX-2 selective inhibitors without a past history of peptic ulcer.

Recommendation: strong, $100 \%$ agreed, evidence level B.

Comment: An MA revealed that the incidence of druginduced peptic ulcer development was similar between patients who received COX-2 selective inhibitors and placebos, suggesting that COX-2 selective inhibitors do not increase the risk of drug-induced peptic ulcers [60-62]. In a network MA, concomitant dosing of COX-2 selective inhibitors with PPIs effectively prevented the development of drug-induced peptic ulcer compared with COX-2 selective inhibitors alone [63]. However, patients with a history of peptic ulcers have a higher risk of developing drug-induced peptic ulcers.

\section{LDA-induced ulcer}

\section{Treatment}

$C Q-18$

How should LDA-related peptic ulcers be treated?

- Concomitant use of PPIs with continuous LDA therapy is recommended for LDA-related peptic ulcers.
Recommendation: strong, $100 \%$ agreed, evidence level A.

Comment: For patients with a history of LDA-related PUB, concomitant use of PPIs with continuous LDA therapy after endoscopic hemostasis was equivalent in the recurrence of PUB compared to concomitant use of placebos and PPIs. Furthermore, continuous LDA therapy reduces overall mortality rates related to cardiovascular (CV) events [8]. In the same study, concomitant use of PPIs with continuation of LDA therapy did not increase the incidence of PUB recurrence [8]. The peptic ulcer healing rate was similar between the PPI alone and the LDA combined with PPI [64].

Prevention.

\section{$C Q-19$}

What kind of concomitant use of medicine should be effective for reducing the incidence and prevalence of LDA-related peptic ulcers?

- PPIs or $\mathrm{H}_{2} \mathrm{RAs}$ is recommended for the reduction of the incidence and prevalence of LDA-related peptic ulcers. Recommendation: strong, $100 \%$ agreed, evidence level A.

(PPIs and $\mathrm{H}_{2} \mathrm{RAs}$ are not covered by Japanese insurance for primary prevention of ulcers in patients taking LDA).

$\left(\mathrm{H}_{2} \mathrm{RAs}\right.$ are not covered by Japanese insurance for secondary prevention of ulcers in patients taking LDA). Comment: MA indicated that LDA treatment with concomitant use of $\mathrm{H}_{2} \mathrm{RAs}$ or PPIs reduced the risk of LDA-related peptic ulcers [65, 66]. PPIs were superior to $\mathrm{H}_{2} \mathrm{RAs}$ in preventing upper GI ulcers related to LDA [67]. However, a RCT by Chan et al. [68] indicated that there were no significant differences between rabeprazole and famotidine in the incidence of recurrent ulcers in patients taking LDA. We used data from two RCTs $[69,70]$ in Mo et al. [67] and one RCT [68] to independently conduct an MA. We found no significant difference (RR 0.26; 95\% CI 0.04-1.81, $P=0.17$ ) in the incidence of LDA-related upper GI ulcers between PPIs and $\mathrm{H}_{2}$ RAs (Fig. 7).

\section{$C Q-20$}

What kind of concomitant use of medicine should be effective for reducing the incidence and prevalence rate of LDA-related PUB?

- PPIs or VPZ is recommended for the reduction of the incidence and prevalence of LDA-related PUB. 


\begin{tabular}{|c|c|c|c|c|c|c|c|c|c|c|c|}
\hline \multirow[b]{2}{*}{ Study or Subgroup } & \multicolumn{2}{|c|}{ PPI } & \multicolumn{2}{|c|}{ H2RA } & \multicolumn{3}{|c|}{ Risk Ratio } & \multirow{2}{*}{\multicolumn{4}{|c|}{$\begin{array}{c}\text { Risk Ratio } \\
\text { M-H, Random, } 95 \% \mathrm{Cl}\end{array}$}} \\
\hline & Events & Total & Events & Total & Weight & M-H, Random, $95 \% \mathrm{Cl}$ & Year & & & & \\
\hline $\operatorname{Ng} 2010$ & 0 & 65 & 6 & 65 & $25.4 \%$ & $0.08[0.00,1.34]$ & 2010 & & 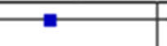 & & \\
\hline $\operatorname{Ng} 2012$ & 0 & 163 & 5 & 148 & $25.1 \%$ & $0.08[0.00,1.48]$ & 2012 & & & & \\
\hline Chan 2017 & 8 & 138 & 9 & 132 & $49.5 \%$ & $0.85[0.34,2.14]$ & 2017 & & & & \\
\hline Total $(95 \% \mathrm{Cl})$ & & 366 & & 345 & $100.0 \%$ & $0.26[0.04,1.81]$ & & & & & \\
\hline Total events & 8 & & 20 & & & & & & & & \\
\hline $\begin{array}{l}\text { Heterogeneity. Tauz } \\
\text { Test for overall effec }\end{array}$ & $\begin{array}{l}1.79 ; \mathrm{Ch} \\
\mathrm{Z}=1.36\end{array}$ & $\begin{array}{l}=4.91 \\
P=0.1\end{array}$ & $\begin{array}{l}\text { 1, } d f=2( \\
7)\end{array}$ & $P=0.0$ & $9) ;\left.\right|^{2}=59$ & & & 0.001 & $\begin{array}{c}0.1 \\
\text { Favours PPI }\end{array}$ & $\begin{array}{c}10 \\
\text { Favours } \mathrm{H}_{2}\end{array}$ & 1000 \\
\hline
\end{tabular}

Fig. 7 Effects of proton pump inhibitors (PPIs) and histamine 2-receptor antagonists $\left(\mathrm{H}_{2} \mathrm{RAs}\right)$ in preventing upper gastrointestinal (GI) ulcers related to low dose aspirin (LDA). An independently

Recommendation: strong, $100 \%$ agreed, evidence level A.

(PPI and VPZ are not covered by Japanese insurance for primary and secondary prevention of PUB in patients taking LDA).

Comment: MA revealed that LDA treatment with concomitant use of $\mathrm{H}_{2}$ RAs or PPIs reduced the risk of LDA-related PUB [65, 71]. PPIs were superior to $\mathrm{H}_{2}$ RAs in preventing upper GI ulcer bleeding related to LDA [66, 67]. We used data from three RCTs [68-70] in Mo et al. [67] and three RCTs [72-74], which compared PPIs and $\mathrm{H}_{2} \mathrm{RAs}$ to independently conduct an MA. We found that PPIs were superior to $\mathrm{H}_{2} \mathrm{RAs}$ ( $\mathrm{RR}$ 0.28 ; $95 \%$ CI $0.16-0.50, P<0.0001)$ in the prevention of LDA-related upper GI bleeding (Fig. 8). Furthermore, the incidence of bleeding in the stomach or duodenum was significantly lower with both $10 \mathrm{mg}$ and $20 \mathrm{mg}$ of VPZ compared to $15 \mathrm{mg}$ of lansoprazole in patients taking LDA with a history of ulcers [7].

\section{$C Q-21$}

What kind of concomitant use of medicine should be effective for reducing the incidence and prevalence rate of recurrent LDA-related PUB? meta-analysis demonstrates that no significant difference (RR 0.26 ; 95\% CI 0.04-1.81, $P=0.17$ ) in the incidence of LDA-related upper GI ulcers between PPIs and $\mathrm{H}_{2}$ RAs

- PPIs in addition to the eradication of $H$. pylori infection are recommended for the reduction of the incidence and prevalence rate of LDA-related PUB.

Recommendation: strong, $100 \%$ agreed, evidence level B.

(PPI is not covered by Japanese insurance for second prevention of peptic ulcer bleeding in patients taking LDA).

- $\mathrm{H}_{2} \mathrm{RAs}$ in addition to the eradication of $H$. pylori infection are suggested for the reduction of the incidence and prevalence rate of LDA-related PUB.

Recommendation: weak, $100 \%$ agreed, evidence level C.

$\left(\mathrm{H}_{2} \mathrm{RAs}\right.$ are not covered by Japanese insurance for second prevention of PUB in patients taking LDA).

Comment: The eradication of $H$. pylori is equivalent in the probability of recurrent bleeding to treatment with omeprazole in patients receiving LDA [75]. In patients with ulcer complications related to the long-term use of LDA, treatment with lansoprazole in addition to the eradication of $H$. pylori significantly reduced recurrence rates of ulcer bleeding compared to placebo plus H. pylori eradication [76]. In patients with LDA-related peptic ulcers, high-dose famotidine therapy is inferior to pantoprazole in preventing recurrent ulcer bleeding that continues to receive LDA [69]. LDA treatment

\begin{tabular}{|c|c|c|c|c|c|}
\hline \multirow[b]{2}{*}{ Study or Subgroup } & \multicolumn{2}{|c|}{ PPI } & \multicolumn{2}{|c|}{ H2RA } & \multirow[b]{2}{*}{ Weight } \\
\hline & Events & Total & Events & Total & \\
\hline Ng 2010 & 0 & 65 & 5 & 65 & $4.2 \%$ \\
\hline Tunggal 2011 & 0 & 44 & 2 & 44 & $3.8 \%$ \\
\hline Yano 2012 & 0 & 65 & 1 & 65 & $3.4 \%$ \\
\hline $\mathrm{Ng} 2012$ & 3 & 163 & 12 & 148 & $22.3 \%$ \\
\hline Wang Z 2013 & 10 & 163 & 14 & 77 & $59.0 \%$ \\
\hline Chan 2017 & 1 & 138 & 4 & 132 & $7.3 \%$ \\
\hline Total $(95 \% \mathrm{CI})$ & & 638 & & 531 & $100.0 \%$ \\
\hline Total events & 14 & & 38 & & \\
\hline $\begin{array}{l}\text { Heterogeneity. Tau² } \\
\text { Test for overall effec }\end{array}$ & $\begin{array}{l}0.00 ; \mathrm{Ch} \\
\mathrm{Z}=4.25\end{array}$ & $\begin{array}{l}I^{2}=1.08 \\
(P<0.0\end{array}$ & $\begin{array}{l}6, d f=5(f \\
001)\end{array}$ & $=0.9$ & $6) ; 1^{2}=0$ \\
\hline
\end{tabular}

Fig. 8 Effects of proton pump inhibitors (PPIs) and histamine 2-receptor antagonists $\left(\mathrm{H}_{2} \mathrm{RAs}\right)$ in preventing upper gastrointestinal (GI) ulcer bleeding related to low dose aspirin (LDA). An
Risk Ratio

Year

$0.09[0.01 .1 .61] 2010$

$0.20[0.01,4.05] 2011$

$0.33[0.01,8.03] 2012$

$0.23[0.07,0.79] 2012$

$0.34[0.16,0.73] 2013$

$0.24[0.03,2.11] 2017$

$0.28[0.16,0.50]$

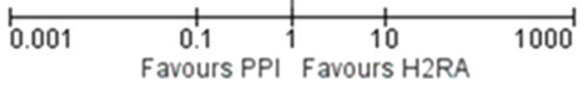

independently meta-analysis demonstrated that PPIs are superior to $\mathrm{H}_{2} \mathrm{Ras}$ (RR 0.28 ; 95\% CI $0.16-0.50, P<0.0001$ ) in prevention of LDA-related upper GI bleeding 
with concomitant use of rabeprazole showed no difference in the incidence of recurrent upper GI ulcer bleeding rates compared to famotidine in patients with a history of LDA-related peptic ulcer bleeding [68].

\section{$C Q-22$}

How should LDA-related peptic ulcer recurrence be prevented in patients with a history of peptic ulcers?

- PPI or VPZ is recommended to reduce the recurrence rate of LDA-related peptic ulcers.

Recommendation: strong, $100 \%$ agreed, evidence level A.

- $\mathrm{H}_{2} \mathrm{RAs}$ are suggested to reduce the recurrence rate of LDA-related peptic ulcers.

Recommendation: weak, $100 \%$ agreed, evidence level C.

Comment: In patients with a history of LDA-related peptic ulcers who continued to receive LDA, pantoprazole was superior to famotidine in preventing recurrent bleeding ulcers [69]. LDA treatment with concomitant use of $20 \mathrm{mg}$ rabeprazole showed no difference in the recurrence of upper GI ulcer bleeding compared to $40 \mathrm{mg}$ of famotidine in patients with a history of LDA-related PUB [68]. An independent MA of four RCT articles [77-80] demonstrated that PPIs were superior to control drugs, placebos, gefarnate, and teprenone, in preventing the recurrence of LDA-related upper GI ulcers (RR 0.09; 95\% CI 0.06-0.15, $P<0.00001)$. A study found that $47-53 \%$ of patients with gastroduodenal ulcer scars on endoscopy at baseline, famotidine was superior to placebo in prevention of the incidence of gastroduodenal ulcers in patients taking LDA [81]. An RCT by Kawai et al. indicated that $10 \mathrm{mg}$ of VPZ was superior to $15 \mathrm{mg}$ of lansoprazole in the prevention of peptic ulcer recurrence in patients with a history of peptic ulcers who required LDA [7].

\section{$C Q-23$}

In patients without a history of peptic ulcer, is the prevention of LDA-related peptic ulcers necessary?

- PPIs are recommended for the primary prevention of LDA-related peptic ulcers without a history of ulcers. Recommendation: strong, $82 \%$ agreed, evidence level A.

Comment: In an RCT by Takeuchi et al., famotidine was superior to teprenone in reducing the number of erosions during LDA use in $94 \%$ of patients without a history of peptic ulcers [82]. Scheiman et al. [83] indicated that esomeprazole reduced the occurrence of peptic ulcers in patients taking LDA in $73 \%$ of patients without a history of peptic ulcers. $\mathrm{Ng}$ et al. [70] found that esomeprazole was superior to famotidine in preventing upper GI complications related to LDA, clopidogrel, and thrombolytics in $95 \%$ of patients without a peptic ulcer.

\section{$C Q-24$}

Can COX-2 selective inhibitors reduce the risk of peptic ulcers compared to nonselective NSAIDs when administered with LDA?

- COX-2 selective inhibitors reduce the risk of peptic ulcers and bleeding in patients taking LDA compared to nonselective NSAIDs.

Recommendation: strong, $100 \%$ agreed, evidence level A.

- Concomitant use of celecoxib with PPIs is recommended for the prevention of gastric injury in patients with moderate or lower risk of peptic ulcers requiring LDA and NSAIDs.

Recommendation: strong, $100 \%$ agreed, evidence level A.

Comment: Concomitant use of a COX-2 selective inhibitor with LDA increased the incidence of peptic ulcers [84], whereas COX-2 selective inhibitors lowered the risk of peptic ulcers compared to nonselective NSAIDs when using LDA [85, 86]. In patients taking LDA, the use of celecoxib or naproxen with PPIs resulted in similar rates of gastroduodenal ulceration [87]. In patients at high risk of both CV and GI events requiring concomitant LDA and NSAIDs, celecoxib with PPIs was the preferred treatment to reduce the risk of recurrent upper GI bleeding compared to naproxen with esomeprazole [88]. A study found that in $45 \%$ of arthritis patients taking LDA, the risk of GI events was lower with celecoxib than with naproxen or ibuprofen [89]. COX-2 selective inhibitors and nonselective NSAIDs increased the risk and incidence of $\mathrm{CV}$ events [90], whereas celecoxib was non-inferior to naproxen or ibuprofen with regard to CV safety [88, 89]. In addition, the American College of Gastroenterology (ACG) guidelines suggest that concomitant use of COX-2 selective inhibitors or nonselective NSAIDs in patients taking LDA should not be prescribed in patients at high risk of peptic ulcer [91]. 
$C Q-25$

Is PPI recommended for the prevention of recurrence of peptic ulcers with NSAID treatment in patients taking LDA?

- Celecoxib with concomitant use of PPI is recommended for the prevention of peptic ulcer recurrence after NSAID treatment in patients taking LDA.

Recommendation: strong, $100 \%$ agreed, evidence level A.

(PPI is not covered by Japanese insurance for the primary prevention of ulcers in patients taking LDA).

Comment: In patients with a history of ulcer who are receiving combinations of NSAIDs and LDA, concomitant use of PPI lowered the risk for gastric ulcer recurrence as misoprostol [92]. In addition, Goldstein et al. indicated that naproxen with esomeprazole lowered the incidence of gastric ulcers compared to naproxen in LDA users [93]. There were fewer GI events in patients using both COX-2 inhibitors and LDA than nonselective NSAIDs and LDA [85, 86], and there were no differences in the occurrence of $\mathrm{CV}$ events between celecoxib and naproxen or ibuprofen $[88,89]$.

\section{Non-H. pylori, non-NSAIDs ulcer}

\section{$C Q-26$}

How should non- $H$. pylori and non-NSAIDs ulcers be treated?

- PPIs are suggested for the initial treatment of non- $H$. pylori and non-NSAID idiopathic ulcers with PPIs or $\mathrm{H}_{2} \mathrm{RAs}$ for the prevention of recurrence.

Recommendation: weak, $100 \%$ agreed, evidence level: C.

Comment: As hyperacidity and hypergastrinemia have been observed in patients with idiopathic ulcers [94], we suggest PPIs as the initial treatment. However, Kanno et al. [95] reported that the healing rate at 12 weeks with PPIs was $77.4 \%$ for idiopathic ulcers compared to $95.0 \%$ for $H$. pylori ulcers. Therefore, PPIs may be insufficient for the treatment of idiopathic ulcers. Wong et al. [96] reported that the cumulative recurrence rate of the idiopathic ulcer group for 7 years without preventive treatment was $42.3 \%$, higher than that of the H. pylori ulcer group (11.2\%). Furthermore, in the following RCT conducted by them, they compared the efficacy of PPI and $\mathrm{H}_{2} \mathrm{RA}$ in preventing recurrence of idiopathic ulcers and reported that the cumulative incidence of upper GI bleeding at
24 months was $0.88 \%$ for PPI (lansoprazole: $30 \mathrm{mg}$ once per day) and $2.63 \%$ for $\mathrm{H}_{2} \mathrm{RA}$ (famotidine: $40 \mathrm{mg}$ once per day) The effect was not significantly different between the two groups $(P=0.336)$ [97]. Therefore, we suggest that both PPIs and $\mathrm{H}_{2}$ RAs are candidates for the prevention of recurrence.

\section{Remnant gastric ulcer}

$C Q-27$

What is the treatment for ulcers in the gastric remnant?

- PPI treatment is recommended for ulcers in the gastric remnant.

Recommendation: strong, $100 \%$ agreed, evidence level C.

Comment: The first choice for the treatment of ulcers in gastric remnant is drug therapy. In an open-label trial comparing omeprazole, cimetidine, sucralfate, colloidal bismuth, and misoprostol for ulcers in the gastric remnant, omeprazole was the best in terms of cure rate and cure speed [98]. The cure rates of ulcer in 2 weeks' treatment were $66.7,43.3,22.2,22.2$, and $16.7 \%$ for omeprazole, cimetidine, sucralfate, colloidal bismuth, and misoprostol, respectively.

To date, there has not been a RCT regarding the $H$. pylori eradication effect. However, in several crosssectional studies comparing the $H$. pylori positivity rate between gastric remnants with and without ulcers, there was no difference [99-102]. From these results, the eradication effect for ulcer occurrence in the gastric remnant is unknown. The preventive effect of eradication for carcinogenesis in the gastric remnant is also undefined. However, speculating from histological improvement after eradication, it would be effective for preventing carcinogenesis. We should be cautious about the recovery of acid secretion after eradication for ulcer occurrence in the gastric remnant.

\section{Surgical treatment}

$C Q-28$

Is eradication of $H$. pylori recommended after surgery for peptic ulcers?

- Eradication of H. pylori is recommended after omental patch or omental filling procedure for peptic ulcers if $H$. pylori positive.

Recommendation: strong, $100 \%$ agreed, evidence level A.

Comment: For post-surgery treatment, reports 
regarding eradication therapy were found, but not for PPI or $\mathrm{H}_{2} \mathrm{RA}$ treatment. Several reports were in agreement with the recommendation of eradication therapy for prevention of peptic ulcer recurrence after stomach preserving surgery [103-107]. El-Nakeeb et al. [107] indicated that early eradication after omental patch surgery for duodenal ulcer perforation is recommended for accelerating ulcer healing 8 weeks after surgery.

Preventive effects for ulcer recurrence by eradication after gastrectomy were not consistent between reports. Further analysis is needed to determine the effect of acid secretion recovery after eradication of peptic ulcers.

\section{$F R Q-1$}

What is the treatment for an ischemic duodenal ulcer?

- Suggested PPIs or misoprostol as conservative treatments. Background conditions such as thrombosis and arterial stenosis should be investigated. IVR or surgery may be considered if the patient's condition is exacerbated following conservative treatment.

Comment: Fourteen case reports regarding ischemic duodenal ulcers were identified. Symptoms included acute onset abdominal pain, melena or hematemesis, chronic abdominal pain, and weight loss. Typical endoscopic findings for ischemia were longitudinal ulcers, and edematous and reddish changes in the surrounding mucosa other than the ulcer. The causes of acute ischemia include embolization for GI bleeding hemostasis or embolization therapy for hepatocellular carcinoma, systemic thromboembolism [108, 109], and unknown cases. Chronic symptoms were reported in patients at risk of atherosclerotic disease and severe stenosis of the celiac artery/superior mesenteric artery. Fasting and acid-secreting inhibitors have been used as conservative treatments. However, the clinical effectiveness of acid suppression in the posterior part of the bulb, which is exposed to bile and pancreatic juice, remains unclear. From the viewpoint of mucosal protection, misoprostol is suggested. In the case of acute onset ischemic ulcers, careful observation is required, considering the possibility of systemic thrombosis.

\section{Therapeutic algorithm}

Figure 9 shows the algorithm for the treatment of peptic ulcer disease. If complications are present, they are addressed prior to the treatment of the ulcer. Perforation or stenosis is treated with surgery or conservative therapy. Hemorrhagic ulcers are treated via endoscopic hemostasis. When endoscopic hemostasis failed, surgery or IVR is performed. When no complications are present, medical therapy is provided immediately (Fig. 9a).

NSAIDs are discontinued, and anti-ulcer therapy is provided for the treatment of NSAID-induced ulcers. If NSAIDs cannot be discontinued, the ulcer should be treated with a PPI. Patients with peptic ulcers who do not use NSAIDs should be tested for $H$. pylori. Eradication therapy is recommended for patients who are $H$. pylori positive. If first-line therapy fails, second-line therapy is provided. If the second-line therapy fails, a specialist is consulted for third-line therapy. For patients without an indication for eradication therapy, non-eradication therapy is provided followed by maintenance therapy to prevent ulcer recurrence. A remnant gastric ulcer is treated with a PPI, and an idiopathic ulcer is treated with PPI followed by maintenance therapy with a PPI or $\mathrm{H}_{2} \mathrm{RA}$ (Fig. 9b).

${ }^{* 1}$ Contraindications. Only when administration is unavoidable as it cannot be discontinued.

*2Patients who do not use NSAIDs and are H. pylori negative are considered to have idiopathic peptic ulcers.

Figure 10 shows the algorithm for the prevention of NSAID-induced ulcers. In patients with no ulcer history receiving NSAID therapy, celecoxib (CXB) is recommended and PPIs are suggested for ulcer prevention. However, PPIs are recommended for elderly patients and patients with serious complications. If patients are both NSAID-naïve and $H$. pylori positive, eradication therapy is recommended. For patients with a history of ulcers that do not include bleeding who are receiving NSAID therapy, a PPI with or without CXB is recommended, and the administration of VPZ is suggested for the prevention of ulcer recurrence. For patients with a history of hemorrhagic ulcers who are receiving NSAID therapy, CXB with a PPI is recommended. CXB with a PPI is recommended for patients receiving combined NSAID therapy and LDA.

Figure 11 shows the algorithm for the prevention of LDA-related ulcers. PPIs are recommended for ulcer prevention in patients receiving LDA therapy with no ulcer history. For patients with a history of ulcers without bleeding who are receiving LDA therapy, PPIs or VPZ are recommended and $\mathrm{H}_{2}$ RAs are suggested. A PPI is recommended and $\mathrm{H}_{2} \mathrm{RA}$ is suggested for patients with a history of hemorrhagic ulcers who are receiving LDA therapy. However, if the patients are $H$. pylori positive, eradication 
(a)

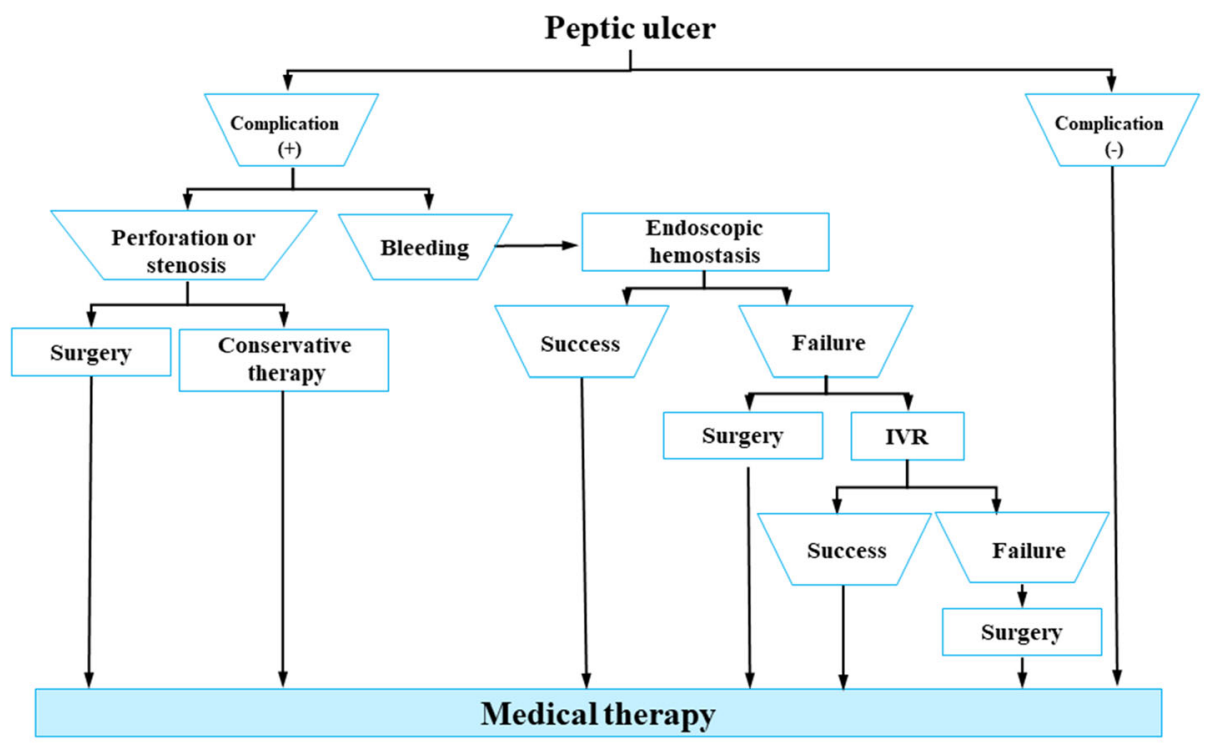

(b)

\section{Medical therapy}

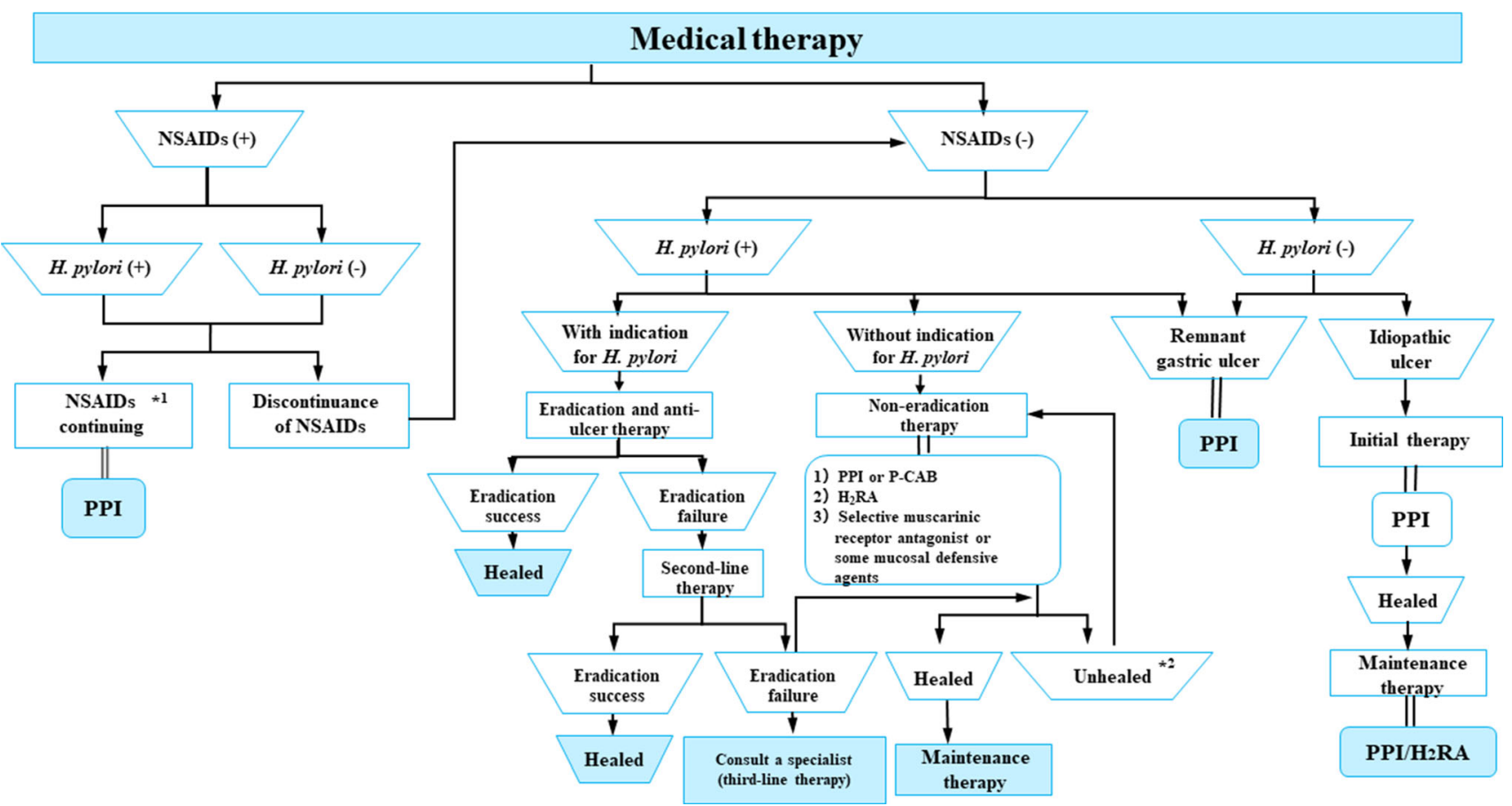

Fig. 9 Algorithm for the treatment of peptic ulcer disease

therapy is recommended. Finally, for patients receiving combinations of LDA and NSAID therapy, CXB with a PPI is recommended.

Acknowledgements This article was supported by a Grant-in-Aid from JSGE. The authors thank the investigators and supporters for participating in the studies. The authors express special appreciation to Mr. Yuji Tatsugami and Miss. Ayari Sada (Nankodo) for their help in creating these guidelines.

Author contributions Writing-original draft: TKa, KS, TI, MI, JI, TO, TKan, MS, TC, SN, MM. Writing-review and editing: TKa and
KS Supervision: HH, JY, AT, SW, and KK Approval of final manuscript: All authors.

\section{Compliance with ethical standards}

Conflict of interest Any financial relationship with enterprises, businesses or academic institutions in the subject matter or materials discussed in the manuscript are listed as follows: (1) those from whom the authors, the spouse, partner or immediate relatives of authors, who have received individually any income, honoraria or any other types of remuneration: Astellas Pharma Inc., AstraZeneca K.K., DaiichiSankyo Company, Limited, Eisai Co., Ltd., Otsuka Pharmaceutical Co.,Ltd., Pfizer Japan Inc., Takeda Pharmaceutical Company Limited. and (2) those from whom the academic institutions of the 


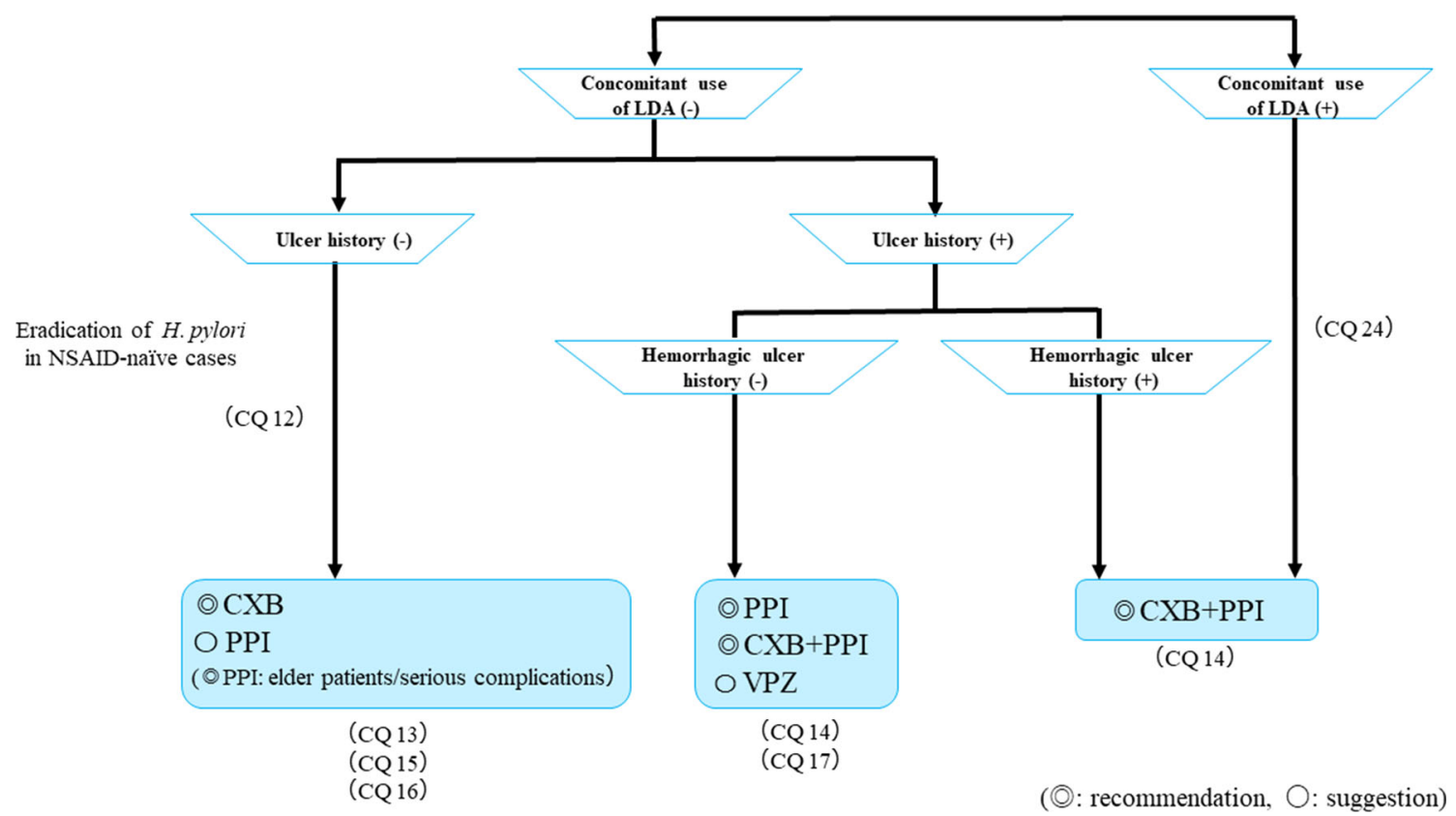

Fig. 10 Algorithm for the prevention of NSAID-induced ulcers

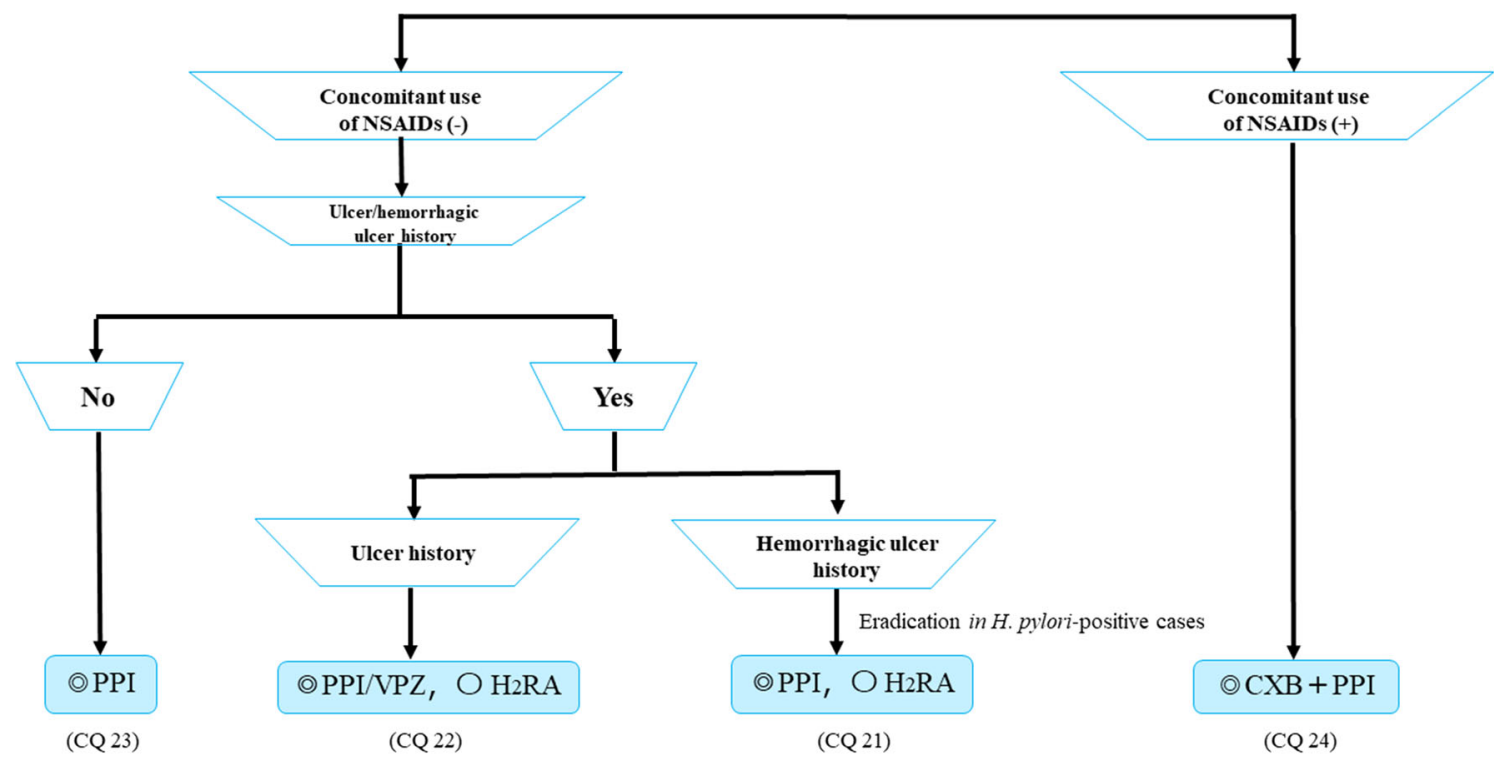

(๑): recommendation, $\bigcirc$ : suggestion)

Fig. 11 Algorithm for the prevention of LDA-related ulcers

authors received support (commercial/academic cooperation): Ajinomoto Pharmaceuticals Co., Ltd., AsTellas Pharma Inc., AstraZenecaK. K., Bayer Yakuhin, Ltd., Chugai PharmaCeutical Co., Ltd., DaiichiSankyo Company, Limited, Eisai Co., Ltd., Kishuhosokawa Co., Ltd., Maruso Co., Ltd, Mitsubishi Tanabe Pharma Corporation, MSD K.K., Nihon Pharmaceutical Co. Ltd., Nippon Shinyaku Co., Ltd., Okahatanoen Co., Ltd., Otsuka Pharmaceutical Co., Ltd., Pfizer Japan Inc., Sanofi K.K., Taiho Pharmaceutical Co., Ltd., Takeda Pharmaceutical.

Open Access This article is licensed under a Creative Commons Attribution 4.0 International License, which permits use, sharing, adaptation, distribution and reproduction in any medium or format, as long as you give appropriate credit to the original author(s) and the source, provide a link to the Creative Commons licence, and indicate if changes were made. The images or other third party material in this article are included in the article's Creative Commons licence, unless indicated otherwise in a credit line to the material. If material is not included in the article's Creative Commons licence and your intended use is not permitted by statutory regulation or exceeds the permitted use, you will need to obtain permission directly from the copyright holder. To view a copy of this licence, visit http://creativecommons. org/licenses/by/4.0/. 


\section{Appendix}

Members of the Guidelines Committee who created and evaluated the JSGE "Evidence-based clinical practice guidelines for peptic ulcer disease $2020^{\prime}$ ' are listed below.

\section{Executive committee}

Chair: Kiichi Satoh (Department of Gastroenterology, International University of Health and Welfare Hospital). Vice-Chair: Tomoari Kamada (Department of Health Care Medicine, Kawasaki Medical School). Members: Toshiyuki Itoh (Education Center for Medicine and Nursing, Shiga University of Medical Science), Masanori Ito (Department of General Internal Medicine, Hiroshima University Hospital), Junichi Iwamoto (Department of Gastroenterology, Tokyo Medical University Ibaraki Medical Center), Tadayoshi Okimoto (Department of Gastroenterology, Faculty of Medicine, Oita University), Takeshi Kanno (Division of Gastroenterology, Tohoku University Hospital), Mitsushige Sugimoto (Department of Gastroenterological Endoscopy, Tokyo Medical University Hospital), Toshimi Chiba (Division of Internal Medicine, Department of Oral Medicine, Iwate, Medical University), Sachiyo Nomura (Department of Gastrointestinal Surgery, Graduate School of Medicine, The University of Tokyo), and Mitsuyo Mieda (Division of Gastroenterology, Department of Medicine, Jichi Medical University).

\section{Evaluation committee}

Chair: Hideyuki Hiraishi (Niigataseirou Hospital).

Vice-Chair: Junji Yoshino (Fujita Medical University).

Member: Atsushi Takagi (Kameda Morinosato Hospital).

\section{The Japanese Society of Gastroenterology}

President: Kazuhiko Koike (Department of Gastroenterology, Graduate School of Medicine, The University of Tokyo). Past President: Tooru Shimosegawa (South Miyagi Medical Center). Director Responsible: Hiroto Miwa (Division of Gastroenterology, Department of Internal Medicine, Hyogo College of Medicine), Nobuyuki Enomoto (First Department of Internal Medicine, Faculty of Medicine, University of Yamanashi).

\section{SR collaborator}

Ryo Ogawa (Department of Gastroenterology, Faculty of Medicine, Oita University), Sotaro Ozaka (Department of Gastroenterology, Faculty of Medicine, Oita University), Yoshinari Kawahara (Department of Gastroenterology, Faculty of Medicine, Oita University), Xiaoyi Jin (Division of Gastroenterology, Tohoku University Hospital), Naoki Sumi (Department of Health Care Medicine, Kawasaki Medical School), Kenichiro Nakagawa (Division of Gastroenterology, Tohoku University Hospital), Kensuke Fukuda (Department of Gastroenterology, Faculty of Medicine, Oita University).

Tomoyuki Boda (Department of Gastroenterology and Metabolism, Graduate School of Biomedical and Health Sciences, Hiroshima University), Hitomi Mizuno (Toyoda Aoba Clinic), Masaki Murata (Department of Gastroenterology, National Hospital Organization, Kyoto Medical Center), Mohammad Yaghoobi (Division of Gastroenterology, Health Sciences Centre, McMaster University, Canada), and Yuan Yuhong (Division of Gastroenterology, Health Sciences Centre, McMaster University, Canada).

\section{Cooperative society}

The Japanese Gastroenterological Association.

Japan Gastroenterological Endoscopy Society.

\section{References}

1. Yoshida M, Kinoshita Y, Watanabe M, et al. JSGE clinical practice guideline 2014: standards, methods, and process of developing guidelines. J Gastroenterol. 2015;50:4-10.

2. Fujimoto K, Fujishiro M, Kato M, et al. Guidelines for gastroenterological endoscopy in patients undergoing antithrombotic treatment. Dig Endosc. 2014;26:1-14.

3. Kato M, Uedo N, Hokimoto S, et al. Guidelines for gastroenterological endoscopy in patients undergoing antithrombotic treatment: 2017 appendix on anticoagulants including direct oral anticoagulants. Dig Endosc. 2018;30:433-40.

4. Murakami K, Sakurai Y, Shiino M, et al. Vonoprazan, a novel potassium-competitive acid blocker, as a component of first-line and second-line triple therapy for Helicobacter pylori eradication: a phase III, randomised, double-blind study. Gut. 2016;65:1439-46.

5. Miwa H, Uedo N, Watari J, et al. Randomised clinical trial: efficacy and safety of vonoprazan vs. lansoprazole in patients with gastric or duodenal ulcers-results from two phase 3 , noninferiority randomised controlled trials. Aliment Pharmacol Ther. 2017;45:240-52.

6. Mizokami Y, Oda K, Funao N, et al. Vonoprazan prevents ulcer recurrence during long-term NSAID therapy: randomised, lansoprazole-controlled non-inferiority and single-blind extension study. Gut. 2018;67:1042-51. 
7. Kawai T, Oda K, Funao N, et al. Vonoprazan prevents low-dose aspirin-associated ulcer recurrence: randomised phase 3 study. Gut. 2018;67:1033-41.

8. Sung JJ, Lau JY, Ching JY, et al. Continuation of low-dose aspirin therapy in peptic ulcer bleeding: a randomized trial. Ann Intern Med. 2010;152:1-9.

9. Tarasconi A, Baiocchi GL, Pattonieri V, et al. Transcatheter arterial embolization versus surgery for refractory non-variceal upper gastrointestinal bleeding: a meta-analysis. World J Emerg Surg. 2019;14:3.

10. Kyaw M, Tse Y, Ang D, et al. Embolization versus surgery for peptic ulcer bleeding after failed endoscopic hemostasis: a metaanalysis. Endos Int Open. 2014;2:E6-14.

11. Selby NM, Kubba AK, Hawkey CJ. Acid suppression in peptic ulcer haemorrhage: a 'meta-analysis.' Aliment Pharmacol Ther. 2000;14:1119-26.

12. Leontiadis GI, Sharma VK, Howden CW. Systematic review and meta-analysis: proton-pump inhibitor treatment for ulcer bleeding reduces transfusion requirements and hospital stay-results from the Cochrane Collaboration. Aliment Pharmacol Ther. 2005;22:169-74.

13. George S, George G, Androniki P, et al. High-dose vs. low-dose proton pump inhibitors post endoscopic hemostasis in patients with bleeding peptic ulcer: a meta-analysis and meta-regression analysis. Turk J Gastroenterol. 2018;29:22-31.

14. Jian Z, Li H, Race NS, et al. Is the era of intravenous proton pump inhibitors coming to an end in patients with bleeding peptic ulcers? Meta-analysis of the published literature. Br J Clin Pharmacol. 2016;82:880-9.

15. Wang J, Yang K, Ma B, et al. Intravenous pantoprazole as an adjuvant therapy following successful endoscopic treatment for peptic ulcer bleeding. Can J Gastroenterol. 2009;23:287-99.

16. Bhatt DL, Cryer BL, Contant CF, COGENT Investigators, et al. Clopidogrel with or without omeprazole in coronary artery disease. N Engl J Med. 2010;363:1909-17.

17. Ren YH, Zhao M, Chen YD, et al. Omeprazole affects clopidogrel efficacy but not ischemic events in patients with acute coronary syndrome undergoing elective percutaneous coronary intervention. Chin Med J. 2011;124:856-61.

18. Wei P, Zhang YG, Ling L, et al. Effects of the short-term application of pantoprazole combined with aspirin and clopidogrel in the treatment of acute STEMI. Exp Ther Med. 2016;12:2861-4.

19. Valgimigli M, Bueno H, Byrne RA, ESC Scientific Document Group; ESC Committee for Practice Guidelines (CPG); ESC National Cardiac Societies, et al. 2017 ESC focused update on dual antiplatelet therapy in coronary artery disease developed in collaboration with EACTS: The Task Force for dual antiplatelet therapy in coronary artery disease of the European Society of Cardiology (ESC) and of the European Association for CardioThoracic Surgery (EACTS). Eur Heart J. 2018;39:213-60.

20. Ray WA, Chung CP, Murray KT, et al. Association of proton pump inhibitors with reduced risk of warfarin-related serious upper gastrointestinal bleeding. Gastroenterology. 2016;151:1105-12.

21. Kato M, Ota H, Okuda M, et al. Guidelines for the management of Helicobacter pylori infection in Japan: 2016 Revised Edition. Helicobacter. 2019;24:e12597.

22. Sugimoto M, Furuta T, Shirai N, et al. Evidence that the degree and duration of acid suppression are related to Helicobacter pylori eradication by triple therapy. Helicobacter. 2007;12:317-23.

23. Sugimoto M, Yamaoka Y. Role of vonoprazan in Helicobacter pylori eradication therapy in Japan. Front Pharmacol. 2018;9:1560.
24. Malfertheiner P, Megraud F, O'Morain CA, et al. Management of Helicobacter pylori infection-the Maastricht V/Florence Consensus Report. Gut. 2017;66:6-30.

25. Murata M, Sugimoto M, Mizuno H, et al. Clarithromycin versus metronidazole in first-line Helicobacter pylori triple eradication therapy based on resistance to antimicrobial agents: meta-analysis. J Clin Med. 2020;9:543.

26. Mansour-Ghanaei F, Joukar F, Naghipour MR, et al. Seven-day quintuple regimen as a rescue therapy for Helicobacter pylori eradication. World J Gastroenterol. 2015;21:661-6.

27. Hsu PI, Tsai FW, Kao SS, et al. Ten-day quadruple therapy comprising proton pump inhibitor, bismuth, tetracycline, and levofloxacin is more effective than standard levofloxacin triple therapy in the second-line treatment of Helicobacter pylori infection: a randomized controlled trial. Am J Gastroenterol. 2017;112:1374-81.

28. Liou JM, Bair MJ, Chen CC, et al. Levofloxacin sequential therapy vs levofloxacin triple therapy in the second-line treatment of Helicobacter pylori: a randomized trial. Am J Gastroenterol. 2016;111:381-7.

29. Tsujimae M, Yamashita H, Hashimura H, et al. A comparative study of a new class of gastric acid suppressant agent named vonoparazan versus esomeprazole for the eradication of Helicobacter pylori. Digestion. 2016;94:240-6.

30. Sakurai K, Suda H, Ido Y, et al. Comparative study: Vonoprazan and proton pump inhibitors in Helicobacter pylori eradication therapy. World J Gastroenterol. 2017;23:668-75.

31. Sue S, Kuwashima H, Iwata Y, et al. The superiority of vonoprazan-based first-line triple therapy with clarithromycin: a prospective multi-center cohort study on Helicobacter pylori eradication. Intern Med. 2017;56:1277-85.

32. Murakami K, Furuta T, Ando T, et al. Multi-center randomized controlled study to establish the standard third-line regimen for Helicobacter pylori eradication in Japan. J Gastroenterol. 2013;48:1128-35.

33. Furuta T, Sugimoto M, Kodaira C, et al. Sitafloxacin-based third-line rescue regimens for Helicobacter pylori infection in Japan. J Gastroenterol Hepatol. 2014;29:487-93.

34. Mori H, Suzuki H, Matsuzaki J, et al. Efficacy of 10-day sitafloxacin-containing third-line therapies for Helicobacter pylori strains containing the gyrA mutation. Helicobacter. 2015;21:286-94.

35. Di Mario F, Battaglia G, Leandro G, et al. Short-term treatment of gastric ulcer: a meta-analytical evaluation of blind trials. Dig Dis Sci. 1996;41:1108-31.

36. Eriksson S, Langstrom G, Rikner L, et al. Omeprazole and H2receptor antagonists in the acute treatment of duodenal ulcer, gastric ulcer and reflux oesophagitis: a meta-analysis. Eur J Gastroenterol Hepatol. 1995;7:467-75.

37. Salas M, Ward A, Caro J. Are proton pump inhibitors the first choice for acute treatment of gastric ulcers? A meta-analysis of randomized clinical trials. BMC Gastroenterol. 2002;2:17.

38. Tunis SR, Sheinhait IA, Schmid CH, et al. Lansoprazole compared with histamine 2-receptor antagonists in healing gastric ulcers: a meta-analysis. Clin Ther. 1997;19:743-57.

39. Echizen H. The first-in-class potassium-competitive acid blocker, vonoprazan fumarate: pharmacokinetic and pharmacodynamic considerations. Clin Pharmacokinet. 2015;55:409-18 ([Epub ahead of print]).

40. Poynard T, Lemaire M, Agostini H. Meta-analysis of randomized clinical trials comparing lansoprazole with ranitidine or famotidine in the treatment of acute duodenal ulcer. Eur $\mathbf{J}$ Gastroenterol Hepatol. 1995;7:661-5.

41. Tildesley G, Ehsanullah RS, Wood JR. Ranitidine in the treatment of gastric and duodenal ulcers associated with non-steroidal anti-inflammatory drugs. Br J Rheumatol. 1993;32:474-8. 
42. Agrawal NM, Campbell DR, Safdi MA, NSAID-Associated Gastric Ulcer Study Group, et al. Superiority of lansoprazole vs ranitidine in healing nonsteroidal anti-inflammatory drug-associated gastric ulcers: results of a double-blind, randomized, multicenter study. Arch Intern Med. 2000;160:1455-61.

43. Hawkey CJ, Karrasch JA, Szczepañski L, Omeprazole vs. Misoprostol for NSAID-induced Ulcer Management (OMNIUM) Group, et al. Omeprazole compared with misoprostol for ulcers associated with nonsteroidal antiinflammatory drugs. N Engl J Med. 1998;338:727-34.

44. Chan FK, To KF, Wu JC, et al. Eradication of Helicobacter pylori and risk of peptic ulcers in patients starting long-term treatment with non-steroidal anti-inflammatory drugs: a randomised trial. Lancet. 2002;359:9-13.

45. Vergara M, Catalan M, Gisbert JP, et al. Meta-analysis: role of Helicobacter pylori eradication in the prevention of peptic ulcer in NSAID users. Aliment Pharmacol Ther. 2005;21:1411-8.

46. Tang CL, Ye F, Liu W, et al. Eradication of Helicobacter pylori infection reduces the incidence of peptic ulcer disease in patients using nonsteroidal anti-inflammatory drugs: a meta-analysis. Helicobacter. 2012;17:286-96.

47. Koch M. Non-steroidal anti-inflammatory drug gastropathy: clinical results with misoprostol. Ital J Gastroenterol Hepatol. 1999;31(Suppl 1):S54-62.

48. Bianchi Porro G, Lazzaroni M, Petrillo M, et al. Prevention of gastroduodenal damage with omeprazole in patients receiving continuous NSAIDs treatment: a double blind placebo controlled study. Ital J Gastroenterol Hepatol. 1998;30:43-7.

49. Taha AS, Hudson N, Hawkey CJ, et al. Famotidine for the prevention of gastric and duodenal ulcers caused by nonsteroidal antiinflammatory drugs. N Engl J Med. 1996;334:1435-9.

50. Scally B, Emberson JR, Spata E, et al. Effects of gastroprotectant drugs for the prevention and treatment of peptic ulcer disease and its complications: a meta-analysis of randomised trials. Lancet Gastroenterol Hepatol. 2018;3:231-41.

51. Koch M, Deiz A, Tarquini M, et al. Prevention of non-steroidal anti-inflammatory drug-induced gastrointestinal mucosal injury: risk factors for serious complications. Digest Liver Dis. 2000;32:138-51.

52. Sugano K, Kontani T, Katsuo S, et al. Lansoprazole for secondary prevention of gastric or duodenal ulcers associated with long-term non-steroidal anti-inflammatory drug (NSAID) therapy: results of a prospective, multicenter, double-blind, randomized, double-dummy, active-controlled trial. J Gastroenterol. 2012;47:540-52.

53. Sugano K, Kinoshita Y, Miwa H, Esomeprazole NSAID Preventive Study Group, et al. Randomised clinical trial: esomeprazole for the prevention of nonsteroidal anti-inflammatory drug-related peptic ulcers in Japanese patients. Aliment Pharmacol Ther. 2012;36:115-25.

54. Chan FK, Wong VW, Suen BY, et al. Combination of a cyclooxygenase- 2 inhibitor and a proton-pump inhibitor for prevention of recurrent ulcer bleeding in patients at very high risk: a double-blind, randomised trial. Lancet. 2007;369:1621-6.

55. Masclee GM, Valkhoff VE, Coloma PM, et al. Risk of upper gastrointestinal bleeding from different drug combinations. Gastroenterology. 2014;147:784-92.

56. Vonkeman HE, Fernandes RW, van der Palen J, et al. Protonpump inhibitors are associated with a reduced risk for bleeding and perforated gastroduodenal ulcers attributable to non-steroidal anti-inflammatory drugs: a nested case-control study. Arthritis Res Ther. 2007;9:R52.

57. Emery P, Zeidler H, Kvien TK, et al. Celecoxib versus diclofenac in long-term management of rheumatoid arthritis: randomized double-blind comparison. Lancet. 1999;354:2106-11.
58. Laine L, Harper S, Simon T, et al. A randomized trial comparing the effect of rofecoxib, a cyclooxygenase 2-specific inhibitor, with that of ibuprofen on the gastroduodenal mucosa of patients with osteoarthritis: Rofecoxib Osteoarthritis Endoscopy Study Group. Gastroenterology. 1999;117:776-83.

59. Pavelka K, Recker DP, Verburg KM. Valdecoxib is as effective as diclofenac in the management of rheumatoid arthritis with a lower incidence of gastroduodenal ulcers: results of a 26-week trial. Rheumatology. 2003;42:1207-15.

60. Sakamoto C, Kawai T, Nakamura S, et al. Comparison of gastroduodenal ulcer incidence in healthy Japanese subjects taking celecoxib or loxoprofen evaluated by endoscopy: a placebocontrolled, double-blind 2-week study. Aliment Pharmacol Ther. 2013;37:346-54.

61. Goldstein JL, Kivitz AJ, Verburg KM, et al. A comparison of the upper gastrointestinal mucosal effects of valdecoxib, naproxen and placebo in healthy elderly subjects. Aliment Pharmacol Ther. 2003;18:125-32.

62. Feng GS, Ma JL, Wong BC, et al. Celecoxib-related gastroduodenal ulcer and cardiovascular events in a randomized trial for gastric cancer prevention. World J Gastroenterol. 2008; 14:4535-9.

63. Yuan JQ, Tsoi KK, Yang M, et al. Systematic review with network meta-analysis: comparative effectiveness and safety of strategies for preventing NSAID-associated gastrointestinal toxicity. Aliment Pharmacol Ther. 2016;43:1262-75.

64. Liu CP, Chen WC, Lai KH, et al. Esomeprazole alone compared with esomeprazole plus aspirin for the treatment of aspirin-related peptic ulcers. Am J Gastroenterol. 2012;107:1022-9.

65. Tricco AC, Alateeq A, Tashkandi M, et al. Histamine H2 receptor antagonists for decreasing gastrointestinal harms in adults using acetylsalicylic acid: systematic review and metaanalysis. Open Med. 2012;6:e109-17.

66. Mo C, Sun G, Lu ML, et al. Proton pump inhibitors in prevention of low-dose aspirin-associated upper gastrointestinal injuries. World J Gastroenterol. 2015;21:5382-92.

67. Mo C, Sun G, Wang Y, et al. PPI versus histamine $\mathrm{H} 2$ receptor antagonists for prevention of upper gastrointestinal injury associated with low-dose aspirin: Systematic review and metaanalysis. PLoS ONE. 2015;10:e0131558.

68. Chan FK, Kyaw M, Tanigawa T, et al. Similar efficacy of proton-pump inhibitors vs $\mathrm{H} 2$-receptor antagonists in reducing risk of upper gastrointestinal bleeding or ulcers in high-risk users of low-dose aspirin. Gastroenterology. 2017;152:105-10.

69. Ng FH, Wong SY, Lam KF, et al. Famotidine is inferior to pantoprazole in preventing recurrence of aspirin-related peptic ulcers or erosions. Gastroenterology. 2010;138:82-8.

70. Ng FH, Tunggal P, Chu WM, et al. Esomeprazole compared with famotidine in the prevention of upper gastrointestinal bleeding in patients with acute coronary syndrome or myocardial infarction. Am J Gastroenterol. 2012;107:389-96.

71. Lanas A, Wu P, Medin J, et al. Low doses of acetylsaiicyiic acid increase risk of gastrointestinal bleeding in a meta-analysis. Clin Gastroenterol Hepatol. 2011;9:762-8.

72. Yano H, Tsukahara K, Morita S, et al. Influence of omeprazole and famotidine on the antiplatelet effects of clopidogrel in addition to aspirin in patients with acute coronary syndromes: a prospective, randomized, multicenter study. Circ J. 2012;76:2673-80.

73. Wang Z, Yang X, Cai J, et al. Influence of different proton pump inhibitors on platelet function in acute myocardial infarction patients receiving clopidogrel treatment after percutaneous coronary intervention. Biomed Res. 2013;24:453-7.

74. Tunggal P, Ng FH, Lam KF, et al. Effect of esomeprazole versus famotidine on platelet inhibition by clopidogrel: a double-blind, randomized trial. Am Heart J. 2011;162:870-4. 
75. Chan FK, Chung SC, Suen BY, et al. Preventing recurrent upper gastrointestinal bleeding in patients with Helicobacter pylori infection who are taking low-dose aspirin or naproxen. N Engl J Med. 2001;344:967-73.

76. Lai KC, Lam SK, Chu KM, et al. Lansoprazole for the prevention of recurrence of ulcer complications from long-term low-dose aspirin use. N Engl J Med. 2002;346:2033-8.

77. Sugano K, Matsumoto Y, Itabashi T, et al. Lansoprazole for secondary prevention of gastric or duodenal ulcers associated with long-term low-dose aspirin therapy: results of a prospective, multicenter, double-blind, randomized, double-dummy, active-controlled trial. J Gastroenterol. 2011;46:724-5.

78. Sanuki T, Fujita T, Kutsumi H, Case Study Group, et al. Rabeprazole reduces the recurrence risk of peptic ulcers associated with low-dose aspirin in patients with cardiovascular or cerebrovascular disease: a prospective randomized active-controlled trial. J Gastroenterol. 2012;47:1186-97.

79. Iwakiri R, Higuchi K, Kato M, et al. Randomised clinical trial: prevention of recurrence of peptic ulcers by rabeprazole in patients taking low-dose aspirin. Aliment Pharmacol Ther. 2014;40:780-95.

80. Sugano K, Choi MG, Lin JT, on behalf of the LAVENDER Study Group, et al. Multinational, double-blind, randomised, placebo-controlled, prospective study of esomeprazole in the prevention of recurrent peptic ulcer in low-dose acetylsalicylic acid users: the LAVENDER study. Gut. 2014;63:1061-8.

81. Taha AS, McCloskey C, Prasad R, et al. Famotidine for the prevention of peptic ulcers and oesophagitis in patients taking low-dose aspirin (FAMOUS): a phase III, randomised, doubleblind, placebo-controlled trial. Lancet. 2009;374:119-25.

82. Takeuchi T, Ota K, Harada S, et al. Comparison of teprenone and famotidine against gastroduodenal mucosal damage in patients taking low-dose aspirin. J Gastroenterol Hepatol. 2014;29(Suppl. 4):11-5.

83. Scheiman JM, Devereaux PJ, Herlitz J, et al. Prevention of peptic ulcers with esomeprazole in patients at risk of ulcer development treated with low-dose acetylsalicylic acid: a randomised, controlled trial (OBERON). Heart. 2011;97:797-802.

84. Laine L, Maller ES, Yu C, et al. Ulcer formation with low-dose enteric-coated aspirin and the effect of COX-2 selective inhibition: a double-blind trial. Gastroenterology. 2004; 127:395-402.

85. Strand V. Are COX-2 inhibitors preferable to non-selective nonsteroidal anti-inflammatory drugs in patients with risk of cardiovascular events taking low-dose aspirin. Lancet. 2007;370:2138-51.

86. Goldstein J, Lowry SC, Lanza FL, et al. The impact of low-dose aspirin on endoscopic gastric and duodenal ulcer rates in users of a non-selective non-steroidal anti-inflammatory drug or a cyclo-oxygenase-2-selective inhibitor. Aliment Pharmacol Ther. 2006;23:1489-98.

87. Goldstein JL, Cryer B, Amer F, et al. Celecoxib plus aspirin versus naproxen and lansoprazole plus aspirin: a randomized, double-blind, endoscopic trial. Clin Gastroenterol Hepatol. 2007;5:1167-74.

88. Chan FKL, Ching JYL, Tse YK, et al. Gastrointestinal safety of celecoxib versus naproxen in patients with cardiothrombotic diseases and arthritis after upper gastrointestinal bleeding (CONCERN): an industry-independent, double-blind, doubledummy, randomised trial. Lancet. 2017;389:2375-82.

89. Nissen SE, Yeomans ND, Solomon DH, et al. Cardiovascular safety of celecoxib, naproxen, or ibuprofen for arthritis. N Engl J Med. 2016;375:2519-29.

90. Mcgettigan P, Henry D. Cardiovascular risk and inhibition of cyclooxygenase: a systematic review of the observational studies of selective and nonselective inhibitors of cyclooxygenase 2. JAMA. 2006;296:1633-44.

91. Lanza FL, Chan FKL, Quigley EMM. Guidelines for prevention of NSAID-related ulcer complications. Am J Gastroenterol. 2009;104:728-38.

92. Goldstein JL, Huang B, Amer F, et al. Ulcer recurrence in highrisk patients receiving nonsteroidal anti-inflammatory drugs plus low-dose aspirin: results of a post Hoc subanalysis. Clin Ther. 2004;26:1637-43.

93. Goldstein JL, Hochberg MC, Fort JG, et al. Clinical trial: the incidence of NSAID-associated endoscopic gastric ulcers in patients treated with PN 400 (naproxen plus esomeprazole magnesium) vs. enteric-coated naproxen alone. Aliment Pharmacol Ther. 2010;32:401-13.

94. Mcoll KEL, LE- Nujumi AM, Chittajallu RS, et al. A study of the pathogenesis of Helicobacter pylori negative chronic duodenal ulceration. Gut. 1993;34:762-8.

95. Kanno T, Iijima K, Abe Y, et al. Helicobacter pylori-negative and non-steroidal anti-inflammatory drugs-negative idiopathic peptic ulcers show refractoriness and high recurrence incidence: multicenter follow-up study of peptic ulcers in Japan. Dig Endosc. 2016;28:556-63.

96. Wong GL, Wong VW, Chan Y, et al. High incidence of mortality and recurrent bleeding in patients with Helicobacter pylori-negative idiopathic bleeding ulcers. Gastroenterology. 2009; 137:525-31.

97. Wong GLH, Lau LHS, Ching JYL, et al. Prevention of recurrent idiopathic gastroduodenal ulcer bleeding: a double-blind, randomised trial. Gut. 2020;69:652-7.

98. Janke A, Stasiewicz J, Namiot Z, et al. Treatment of gastric stump ulcer: an open study with five drugs. Hepatogastroenterology. 2000;47:1195-8.

99. Leivonene MK, Haglund $\mathrm{CH}$, Nordling SFA. Helicobacter pylori infection after partial gastrectomy for peptic ulcer and its role in relapsing disease. Eur $\mathbf{J}$ Gastroenterol Hepatol. 1997;9:371-4.

100. Lee YT, Sung JJ, Choi CL, et al. Ulcer recurrence after gastric surgery: is Helicobacter pylori the culprit? Am J Gastroenterol. 1998;93:928-31.

101. Huang WH, Wang $\mathrm{HH}, \mathrm{Wu} \mathrm{WW}$, et al. Helicobacter pylori infection in patients with ulcer recurrence after partial gastrectomy. Hepatogastroenterology. 2004;51:1551-3.

102. Schilling D, Adamek HE, Wilke J, et al. Prevalence and clinical importance of Helicobacter pylori infection in patients after partial gastric resection for peptic ulcer disease. Z Gastroenterol. 1999;37:127-32.

103. Rodríguez-Sanjuán JC, Fernández-Santiago R, García RA, et al. Perforated peptic ulcer treated by simple closure and Helicobacter pylori eradication. World J Surg. 2005;29:849-52.

104. Ng EK, Lam YH, Sung JJ, et al. Eradication of Helicobacter pylori prevents recurrence of ulcer after simple closure of duodenal ulcer perforation: randomized controlled trial. Ann Surg. 2000;231:153-8.

105. Kate V, Ananthakrishnan N, Badrinath S. Effect of Helicobacter pylori eradication on the ulcer recurrence rate after simple closure of perforated duodenal ulcer: retrospective and prospective randomized controlled studies. Br J Surg. 2001;88:1054-8.

106. Tomtitchong P, Siribumrungwong B, Vilaichone RK, et al. Systematic review and meta-analysis: Helicobacter pylori eradication therapy after simple closure of perforated duodenal ulcer. Helicobacter. 2012;17:148-52.

107. El-Nakeeb A, Fikry A, Abd El-Hamed TM, et al. Effect of Helicobacter pylori eradication on ulcer recurrence after simple closure of perforated duodenal ulcer. Int J Surg. 2009;7:126-9.

108. Force T, MacDonald D, Eade OE, et al. Ischemic gastritis and duodenitis. Dig Dis Sci. 1980;25:307-10. 
109. Julka RN, Aduli F, Lamps LW, et al. Ischemic duodenal ulcer, an unusual presentation of sickle cell disease. J Natl Med Assoc. 2008;100:339-41.
Publisher's Note Springer Nature remains neutral with regard to jurisdictional claims in published maps and institutional affiliations. 